\title{
Synthesis of Iron Doped Zeolite Imidazolate Framework-8 and Its Remazol Deep Black RGB Dye Adsorption Ability
}

\author{
Mai Thi Thanh, ${ }^{1,2}$ Tran Vinh Thien, ${ }^{3}$ Vo Thi Thanh Chau, ${ }^{4}$ Pham Dinh Du, ${ }^{5}$ \\ Nguyen Phi Hung, ${ }^{6}$ and Dinh Quang Khieu ${ }^{1}$ \\ ${ }^{1}$ College of Science, Hue University, Hue City 530000, Vietnam \\ ${ }^{2}$ Faculty of Physics-Chemistry-Biology, Quang Nam University, Tam Ky 560000, Vietnam \\ ${ }^{3}$ Faculty of Natural Science, Phu Yen University, Phu Yen 620000, Vietnam \\ ${ }^{4}$ Faculty of Technology, Industrial University of Ho Chi Minh City, Quang Ngai Campus, Quang Ngai City 570000, Vietnam \\ ${ }^{5}$ Faculty of Natural Science, Thu Dau Mot University, Thu Dau Mot City 820000, Vietnam \\ ${ }^{6}$ Department of Chemistry, Quy Nhon University, Quy Nhon City 590000, Vietnam
}

Correspondence should be addressed to Dinh Quang Khieu; dqkhieu@hueuni.edu.vn

Received 8 February 2017; Revised 20 March 2017; Accepted 28 March 2017; Published 4 May 2017

Academic Editor: Wenshan Guo

Copyright (c) 2017 Mai Thi Thanh et al. This is an open access article distributed under the Creative Commons Attribution License, which permits unrestricted use, distribution, and reproduction in any medium, provided the original work is properly cited.

Zeolite imidazole framework-8 (ZIF-8) and the iron doped ZIF-8 (Fe-ZIF-8) were synthesized by the hydrothermal process. The obtained materials were characteristic of X-ray diffraction (XRD), X-ray photoelectron spectroscopy (XPS), scanning electron microscope (SEM), nitrogen adsorption/desorption isotherms, and atomic absorption spectroscopy (AAS). The results showed that the obtained Fe-ZIF- 8 possessed the ZIF- 8 structure with a large specific area. ZIF- 8 and Fe-ZIF- 8 were used for the removal of Remazol Deep Black (RDB) RGB dye from aqueous solutions. The various factors affecting adsorption such as $\mathrm{pH}$, initial concentration, contact time, and temperature were investigated. The results showed that the introduction of iron into ZIF- 8 provided a much larger adsorption capacity and faster adsorption kinetics than ZIF- 8 without iron. The electrostatic interaction and $\pi-\pi$ interaction between the aromatic rings of the $\mathrm{RDB}$ dye and the aromatic imidazolate rings of the adsorbent were responsible for the RDB adsorption. Moreover, the coordination of the nitrogen atoms and oxygen in carboxyl group in RDB molecules with the $\mathrm{Fe}^{2+}$ ions in the ZIF-8 framework played a vital role for the effective removal of RDB from aqueous solution.

\section{Introduction}

It is well-known that textile industries, pulp mills, and dyestuff manufacturing discharge a considerable amount of colored wastewaters, which has provoked serious environmental concerns all over the world [1]. Its removal is therefore of prime importance. Owing to their complicated chemical structures, dyes are difficult to treat with municipal waste treatment operations. There are many treatment processes such as chemical precipitation, membrane filtration, and alum coagulation of which adsorption is considered the most effective method widely employed to treat wastewater containing different classes of dyes.

Nearly $60 \%$ of the dyes used in textile plants are azo dyes which are classified as mono-, di-, tri-, and tetra-azo dyes, with the azo groups mainly bound to the benzene and naphthalene rings. Remazol Deep Black (denoted as RDB) RGB is a common diazo reactive dye in aqueous solutions and widely used in textile industries [2]. It is stable and hardly biologically degradable due to the presence of aromatic rings. Thus, much research attention has been paid to how to eliminate RDB from aqueous solutions. Various processes including adsorption, electrochemistry, and biosorption for RDB treatment have been reported. Soloman et al. [2] studied the electrochemical degradation of hydrolyzed Remazol Black. Performance of the batch recirculation system was comparatively better than the other rector configurations studied, with respect to capacity utilization and energy consumption. Cardoso et al. [3] used Brazilian pine-fruit shells (Araucaria angustifolia) in natural form and as adsorbents for 


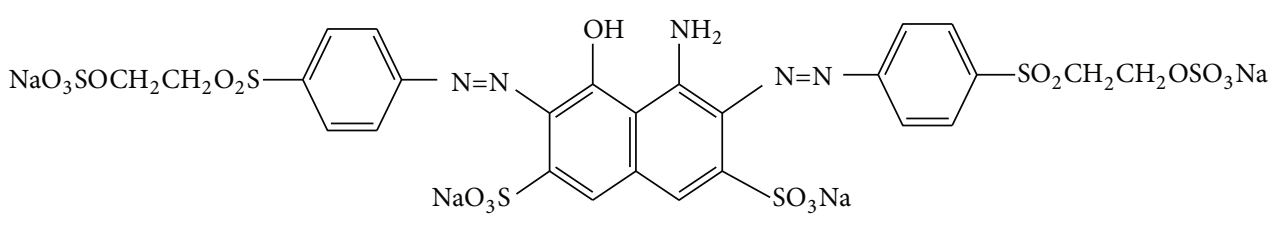

Remazol Deep Black RGB

Scheme 1: The structure of RDB molecule.

the removal of RDB textile dye from aqueous effluents, with a maximum sorption capacity of $74.6 \mathrm{mg} \mathrm{g}^{-1}$. Biosorption of the azo dye by growing fungi (Aspergillus flavus) was investigated in batch reactors. The nearly complete removal of dye was found at initial concentration up to $250 \mathrm{mg} / \mathrm{L}$ and at $\mathrm{pH} 4.5$ which was used as working $\mathrm{pH}$ value for removal of dye in all the batch studies. The removal of chemical oxygen demand (COD) was found to be $90 \%$ at $100 \mathrm{mg} / \mathrm{L}$ initial concentration of dye [4].

Metal-organic frameworks (MOFs) are hybrid materials with ordered three-dimensional frameworks via strong metal-ligand bonds between metal cations and organic linkers [5]. Since their discoveries, MOFs have received significant attention in their potential applications in gas storage [6-13], separation [14, 15], and heterogeneous catalysis [16-19]. The zeolitic imidazolate framework (ZIF) materials have zeolite like topologies and belong to an important class of MOFs materials with interesting adsorption, separation, and catalytic properties [20-23]. Among them, ZIF-8 [ $\mathrm{Zn}(2 \text {-methylimidazole })_{2} \cdot 2 \mathrm{H}_{2} \mathrm{O}$ ] constructed from 2 methylimidazole ligands and $\mathrm{Zn}$ (II) center ions exhibits higher thermal and chemical stability than other MOFs [24]. Many studies show that ZIF-8 exhibited efficient removal of arsenic and organic pollutants from aqueous solutions. Jiang et al. [25] reported that ZIF-8 as a novel adsorbent for fast removal of $1 \mathrm{H}$-benzotriazole and 5-tolyltriazole with regard to adsorption isotherms, kinetics, thermodynamics, desorption, and adsorbent regeneration. Lin and Chang [26] reported that the adsorption capacity of ZIF-8 was much higher than that of fly ash, activated carbon, zeolites, and so forth, showing its promising potential for the removal of humic acid. P-Arsanilic acid which is widely used as feeding additive in the poultry and pork industries to enhance the feeding efficiency was efficiently removed by using ZIF-8 as an adsorbent [27]. ZIF-8 exhibited the high arsenate/arsenite adsorption (up to $50 \mathrm{mg} \cdot \mathrm{g}^{-1}$ for As(II) and $60 \mathrm{mg} \cdot \mathrm{g}^{-1}$ for As $(\mathrm{V}))$ [28]. Zheng et al. [29] reported a free solvent synthesis of core-shell $\mathrm{Fe}_{3} \mathrm{O}_{4}$ @zeolitic imidazolate frameworks-8 (ZIF8) via two steps. The introduction of magnetic iron oxide into ZIF-8 facilitated the separation of adsorbents by the magnetic field. $\mathrm{Fe}_{3} \mathrm{O}_{4} @ Z$ ZIF-8 showed good adsorption properties for methylene blue, with a maximum adsorption capacity of $20.2 \mathrm{mg} \mathrm{g}^{-1}$. According to these studies, ZIF-8 not only is highly stable in water but also exhibits promisingly high adsorption capacities. Owing to these features, ZIF-8 should be promising and feasible adsorbents to organic pollutants from aqueous solutions. On the other hand, in addition to being a catalyst, iron species can act as adsorptive sites for adsorption processes. The combination of iron and ZIF8 (denoted as Fe-ZIF-8) is expected to provide a novel adsorbent due to large accessible surface area and abundant active surface sites.

In this study, the introduction of iron into ZIF-8 by a one-step process was performed with the aim of improving its adsorption ability. Fe-ZIF-8 was used as an adsorbent for removing $\mathrm{RDB}$ dye. In addition, the dye adsorption over ZIF-8 was performed for comparison. The iron oxide incorporated into the ZIF-8 framework significantly enhanced a RDB adsorption capacity compared to bare ZIF-8. A possible adsorption mechanism was suggested, based on adsorption at various $\mathrm{pH}$ values and surface charges on Fe-ZIF-8.

\section{Experimental}

2.1. Materials. Zinc nitrate hexahydrate $\left(\mathrm{Zn}\left(\mathrm{NO}_{3}\right)_{2} \cdot 6 \mathrm{H}_{2} \mathrm{O}\right.$, Daejung, Korea, $\geq 99 \%$ ), iron(II) sulfate heptahydrate $\left(\mathrm{FeSO}_{4} \cdot 7 \mathrm{H}_{2} \mathrm{O}\right.$, Merck, Germany $\left.>99 \%\right)$, methanol $\left(\mathrm{CH}_{3} \mathrm{OH}\right.$, Merck, Germany), and 2-methylimidazole $\left(\mathrm{C}_{4} \mathrm{H}_{6} \mathrm{~N}_{2}\right.$, SigmaAldrich, USA, 99\%) were utilized in this paper. Remazol black B RGB $\left(\mathrm{C}_{26} \mathrm{H}_{21} \mathrm{~N}_{5} \mathrm{Na}_{4} \mathrm{O}_{19} \mathrm{~S}_{6}\right.$, molecular weight = 991.82) was obtained from Thuy Duong Textile Company, Vietnam. The structure of RDB is shown in Scheme 1.

2.2. Preparation of ZIF-8 and Iron Doped ZIF-8 (Fe-ZIF-8). ZIF-8 and Fe-ZIF-8 were synthesized as in [30, 31]. Briefly, $2.8 \mathrm{mmol}$ of zinc(II) and iron(II) (molar ratio of $\mathrm{Fe} / \mathrm{Zn}=0 / 10$ or 1/9) were dissolved in $1.4 \mathrm{mmol}$ of methanol. A solution consisting of $64.4 \mathrm{mmol}$ of 2-methylimidazole and $1.4 \mathrm{~mol}$ of methanol was added to the $\mathrm{Zn}$-Fe based solution and vigorously stirred for 24 hs at ambient temperature. Nitrogen was bubbled through the solution to minimize the oxidation reaction of $\mathrm{Fe}$ (II) to $\mathrm{Fe}(\mathrm{III})$ species. Finally, this solution was centrifuged at $300 \mathrm{rpm}$ and washed thoroughly with methanol. This washing procedure was repeated 3 times. The resultant crystals were dried overnight at $120^{\circ} \mathrm{C}$. The obtained samples with the molar ratio of $\mathrm{Fe}(\mathrm{II}) /(\mathrm{Zn}(\mathrm{II})+\mathrm{Fe}(\mathrm{II}))$ being $0 / 10$ and $1 / 10$ were named ZIF- 8 and Fe-ZIF-8, respectively. In the obtained samples, ZIF- 8 was white and Fe-ZIF- 8 was light brown.

2.3. Determination of the Point of Zero Charge. The $\mathrm{pH}$ at the potential of zero charge $\left(\mathrm{pH}_{\mathrm{PZC}}\right)$ of ZIF-8 and Fe-ZIF8 was measured by the $\mathrm{pH}$ drift method [32]. To a series of $100 \mathrm{~mL}$ flasks, $5 \mathrm{~mL}$ of $0.1 \mathrm{M} \mathrm{NaCl}$ solution and $40 \mathrm{~mL}$ of 
distilled water were added. The initial $\mathrm{pH}$ value ( $\mathrm{pHi}$ ) of the solution was adjusted from 2.3 to 12.0 by adding either $0.1 \mathrm{M}$ $\mathrm{NaOH}$ or $0.1 \mathrm{M} \mathrm{HCl}$. The total volume of solution in each flask was made exactly as $50 \mathrm{~mL}$ by adding distilled water. The $0.01 \mathrm{M} \mathrm{NaCl}$ solutions with different $\mathrm{pH}$ values were obtained. Nitrogen was bubbled through the solution to eliminate the dissolved $\mathrm{CO}_{2}$. Then, 0.02 grams of the sample was added to each flask and mixtures were sealed and shaken for 24 hours; then the final $\mathrm{pH}\left(\mathrm{pH}_{f}\right)$ of solution was recorded. The plot of $\Delta \mathrm{pH}=\mathrm{pH}_{i}-\mathrm{pH}_{f}$ versus initial $\mathrm{pH}_{i}$ was conducted. The point of intersection of curve with abscissa, at which $\Delta \mathrm{pH}=$ 0 , provided $\mathrm{pH}_{\mathrm{PZC}}$.

2.4. Adsorption Kinetics Study. Experiments were conducted in a batch process. The $3 \mathrm{~L}$ plastic beaker was equipped with a stainless steel flat blade impeller using an electric motor to stir the dye solution. Samples (ZIF-8 or Fe-ZIF8) $(0.4 \mathrm{~g})$ were vigorously mixed with $1000 \mathrm{~mL}$ of RDB solution in the beaker at a fixed temperature. Ten millilitres of solution was drawn at preset intervals of time through tap and the solid was removed by centrifuging process. The residual dye concentrations were determined using UV-Vis spectrophotometry. The experiments were conducted with various $\mathrm{RDB}$ concentrations ranging from 30 to $50 \mathrm{ppm}$. The amount of the dye adsorbed by the adsorbent was calculated by the following equation:

$$
q_{t}=\frac{V\left(C_{o}-C_{t}\right)}{m},
$$

where $q_{t}$ is the amount of dye adsorbed per unit of adsorbent amount $\left(\mathrm{mg} \mathrm{g}^{-1}\right)$ at $t$ time, $C_{o}$ the initial dye concentration $\left(\mathrm{mg} \mathrm{L}^{-1}\right), C_{t}$ the dye concentration $\left(\mathrm{mg} \mathrm{L}^{-1}\right)$ after the batch adsorption procedure, $V$ the volume of dye solution (L), and $m$ the mass ( $\mathrm{g}$ ) of the adsorbent. It is reasonably assumed that the adsorption of dye from solution follows reversible firstorder kinetics. The heterogeneous equilibrium between dye in solution and solid adsorbent is illustrated as follows [32]:

$$
\text { dye (solution) } \underset{k_{2}}{\stackrel{k_{1}}{\rightleftarrows}} \text { dye (adsorbent), }
$$

where $k_{1}$ and $k_{2}$ are the forward and backward rate constants, respectively.

The equilibrium constant, $K_{0}$, defined as $k_{1} / k_{2}$ could be expressed [26]

$$
K_{0}=\frac{k_{1}}{k_{2}}=\frac{\left(C_{0}-C_{e}\right)}{C_{e}}
$$

where $C_{0}$ and $C_{e}$ are dye concentrations $\left(\mathrm{mg} \mathrm{L}^{-1}\right)$ at initial and equilibrium time, respectively, and the others are described above.

Pseudo-first-order kinetic of adsorption was investigated by Natarajan-Khalaf equation [33]:

$$
\ln \frac{C_{o}}{C_{t}}=k_{\text {ads }} t
$$

where $k_{\text {ads }}$ is the rate constant of adsorption process.
The slope of the linear plot of $\ln C_{o} / C_{t}$ versus $t$ will provide the value of $k_{\text {ads }}$.

Based on the relaxation method $[34,35], k_{\text {ads }}$ could be expressed as

$$
k_{\text {ads }}=k_{1}+k_{2} \text {. }
$$

Then, the forward and backward rate constants could be derived from (3) and (5).

The kinetics of diffusion was studied by Webber's intraparticle-diffusion model. Webber's intraparticle-diffusion model is described in the following equation $[36,37]$ :

$$
q_{t}=k_{p} \cdot t^{1 / 2}+I
$$

where $k_{p}$ is intraparticle-diffusion rate constant $\left(\mathrm{mgg}^{-1} \min ^{-0.5}\right)$ and $I$ the intercept which reflects the layer boundary effect.

The analysis of the multilinearity in pore and filmdiffusion plot using Webber's plot was conducted by using piecewise linear regression proposed by Malash and ElKhaiary [38].

In this method, the experimental data could be fixed for one, two, or three linear segments' line by Webber's model.

One linear segment's line: $Y=B+A X$ (two parameters).

Two linear segments' line: $Y=B+A X+C(X-D) *$ $\operatorname{sign}(X-D)$ (four parameters).

Three linear segments' line: $Y=B+A X+C(X-D) *$ $\operatorname{sign}(X-D)+E(X-F) * \operatorname{sign}(X-F)$ (six parameters),

where the values of $A, B, C, D, E$, and $F$ are estimated by nonlinear regression. $D$ and $F$ called breakpoints are the boundaries between the segments. The Microsoft Excel "sign" function is defined as follows:

$$
\operatorname{sign}(X-a)= \begin{cases}1 & \text { if } x>a \\ 0 & \text { if } x=a \\ -1 & \text { if } x<a\end{cases}
$$

The example for the two linear segments' equation was expressed as follows:

$$
Y= \begin{cases}B-C D+X(A+C) & \text { if } X>D \\ B+A D & \text { if } x=D \\ B+C D+X(A-C) & \text { if } x<D .\end{cases}
$$

Then the linear equation of the first segment is $y=a_{1} x+b_{1}$, where $b_{1}=B+C D$ and $a_{1}=A-C$.

Then the linear equation of the second segment is $y=$ $b_{2} x+a_{2}$, where $b_{2}=B-C D$ and $a_{2}=A+C$.

Nonlinear regression determines the model's parameters by the least squares method. This is calculated by minimizing the sum of squared deviations, $\mathrm{SSE}_{S}$, by numerical optimization techniques using Solver function in Microsoft Excel. The function for minimization is

$$
\mathrm{SSE}_{S}=\sum_{1}^{N}\left(y_{\mathrm{exp}}-y_{\mathrm{est}}\right)^{2},
$$


where $y_{\text {exp }}$ is experimental datum and $y_{\text {est }}$ is the value estimated by model.

The determination coefficient, $R^{2}$, is obtained by the expression

$$
R^{2}=\frac{1-\mathrm{SSE}_{S}}{\mathrm{SSE}_{T}}
$$

where $\mathrm{SSE}_{T}$ is the total sum of squares equal to $\sum_{1}^{N}\left(y_{\exp }-\right.$ $\left.y_{\text {mean }}\right)^{2}\left(y_{\text {mean }}\right.$ is the mean value of $\left.y\right)$.

The comparison of models was based on Akaike's Information Criterion (AIC) [38-40]. The $\mathrm{AIC}_{\mathrm{c}}$ determines how well the data support each model. The value of AIC can be positive or negative. The model with the lowest AICs score is most likely correct. The $\mathrm{AIC}_{\mathrm{c}}$ (for a small size sample) is calculated for each model from the following equations:

$$
\mathrm{AIC}_{\mathrm{c}}=N \ln \left(\frac{\mathrm{SSE}_{T}}{N}\right)+2 N_{p}+\frac{2 N_{p}\left(N_{p}+1\right)}{N-N_{p}-1},
$$

where $N$ is the number of experimental points and $N_{p}$ is the parameter sum of model.

2.5. Thermodynamic and Isothermal Studies. Experimental procedure was conducted as an adsorption kinetics study. However, the temperature of the process was fixed at 298, 308 , and $318 \mathrm{~K}$. The activation energy, $E_{a}$, was determined by Arrhenius equation [35]:

$$
k=A e^{-E_{a} / R T},
$$

where $k$ is the rate constant equal to the rate constant $k_{\text {ads }}$ in Natarajan and Khalaf equation, $A$ the frequency factor, $R$ gas constant $\left(8.315 \mathrm{~J} \mathrm{~mol}^{-1} \mathrm{~K}^{-1}\right)$, and $T$ absolute temperature in Kelvin.

Taking the natural logarithm of both sides of (12), one obtains

$$
\ln k=-\frac{E_{a}}{R T}+\ln A
$$

By linear plotting $\ln k$ versus $1 / T$, the $E_{a}$ could be obtained from slope $\left(-E_{a} / R\right)$.

Thermodynamic parameters of activation can inform whether or not the adsorption process follows an activated complex or is prior to the final adsorption. Thermodynamic parameters of activation including the enthalpy $\left(\Delta H^{\sharp}\right)$, entropy $\Delta E^{\#}$, and free energy Gibbs $\Delta G^{\#}$ of activation for $\mathrm{RBB}$ adsorption kinetics were obtained by applying Eyring equation $[41,42]$. follows:

The Eyring equation in its thermodynamic version is as

$$
k=\left(\frac{k_{b} T}{h}\right) e^{-\Delta G / R T}=\left(\frac{k_{b} T}{h}\right) e^{\Delta S^{\#} / R} \cdot e^{-\Delta H^{*} / R T},
$$

where $k$ is the rate constant equal to the rate constant $k_{\text {ads }}$ in Natarajan-Khalaf equation, the $k_{b}\left(1.3807 \times 10^{-23} \mathrm{~J} \mathrm{~K}^{-1}\right)$ the Boltzmann constant, and $h\left(6.621 \times 10^{-34} \mathrm{~J} \mathrm{~s}\right)$ the Planck constant.
Taking the natural logarithm of both sides of (14), Eyring equation in linear form was obtained:

$$
\ln \left(\frac{k}{T}\right)=\ln \left(\frac{k_{b}}{h}\right)+\frac{\Delta S^{\#}}{R}-\frac{\Delta H^{\#}}{R T} .
$$

By linear plotting $\ln (k / T)$ versus $1 / T, \Delta S^{\#}$ and $\Delta H^{\#}$ were obtained from the slope $\left(\Delta H^{\#} / T\right)$ and $y$-intercept $\left[\ln \left(k_{b} / h\right)+\right.$ $\left.\left(\Delta S^{\#} / R\right)\right]$.

The Gibbs free energy of activation can be obtained by

$$
\Delta G^{\#}=\Delta H^{\#}-T \Delta S^{\#} .
$$

In order to assess if the adsorption process is spontaneous or not, the thermodynamic parameters of adsorption are needed. The standard Gibbs free energy of adsorption $\left(\Delta G^{0}\right)$ is given by the expression $[35,43]$

$$
\Delta G^{0}=\Delta H^{0}-T \Delta S^{0},
$$

where $\Delta G^{0}, \Delta H^{0}$, and $\Delta S^{0}$ are the standard Gibbs free energy, enthalpy, and entropy, respectively.

$\Delta G^{0}$ is given by van't Hoff's equation:

$$
\Delta G^{0}=-R T \ln K_{d}
$$

where $K_{d}$ is the distribution coefficient of the solute ions and equals $\left(q_{e} / C_{e}\right)[27,44,45]$, and the others are described above.

By replacing (18) with (17), one obtains

$$
\ln K_{d}=-\frac{\Delta H^{0}}{R T}+\frac{\Delta S^{0}}{R} .
$$

The value of $\Delta H^{0}$ and $\Delta S^{0}$ was determined from the slope and intercept of the linear plot of $\ln K_{d}$ versus $1 / T$.

The adsorption isotherms were developed at $25^{\circ} \mathrm{C}$. The adsorption time was conducted for 24 hours to confirm saturation. Thereafter supernatant liquid was collected by centrifugation and the final dye concentrations were determined using UV-Vis spectrophotometry.

The experimental data were analyzed according to the Freundlich and Langmuir models.

Langmuir Isotherm. The Langmuir equation is valid for monolayer sorption onto the surface. It could be expressed as follows [37, 46]:

$$
q_{e}=\frac{K_{L} \cdot q_{\mathrm{mom}} \cdot C_{e}}{1+K_{L} \cdot C_{e}},
$$

where $q_{\text {mom }}$ is the maximum monolayer capacity amount $\left(\mathrm{mg} \mathrm{g}^{-1}\right), K_{L}$ is Langmuir equilibrium constant $\left(\mathrm{L} \mathrm{mg}^{-1}\right)$, and the others are described above.

The essential characteristics of the Langmuir isotherm can be expressed in terms of a dimensionless constant separation factor, $R_{L}$, which is performed as

$$
R_{L}=\frac{1}{\left(1+C_{o} \cdot K_{L}\right)}
$$


where the value of $R_{L}$ indicates the type of isotherm: unfavorable $\left(R_{L}>1\right)$, linear $\left(R_{L}=1\right)$, favorable $\left(0<R_{L}<1\right)$, or irreversible $\left(R_{L}=0\right)$ [47].

Freundlich Isotherm. Freundlich equation is an empirical relation based on the adsorption of adsorbates onto the heterogeneous surface. It is represented as follows $[48,49]$ :

$$
q_{e}=K_{F} \cdot C_{e}^{1 / n},
$$

where $K_{F}$ is the Freundlich constant, which is a measure of adsorption capacity and $n$ an empirical parameter related to the nature and strength of the adsorption process. A large value of $n$ means that the surface is heterogeneous. For values in the range $1<n<10$, adsorption is favorable. Values of $n$ between 2 and 10 represent good adsorption processes, whereas $1<n<2$ indicates that adsorption capacity is only slightly suppressed at lower equilibrium concentrations [50].

The parameters of models ((20) and (22)) were estimated by nonlinear regression method using Solver function in Microsoft Excel. To quantitatively compare the applicability of each model, apart from the regression coefficient $\left(R^{2}\right)$, the Chi-square test $\left(\chi^{2}\right)$ was calculated as follows [51]:

$$
\chi^{2}=\sum \frac{\left(q_{e, \exp }-q_{e, \text { est }}\right)^{2}}{q_{e, \text { est }}},
$$

where $q_{e, \text { exp }}$ and $q_{e, \text { est }}$ are the adsorption capacity at the equilibrium experimental condition and adsorption capacity estimated by model, respectively.

A small value of $\chi^{2}$ indicates that the data obtained from the model is consistent with the experimental value.

2.6. Characterization of Materials. The powder X-ray diffraction (XRD) patterns were recorded by a D8 Advance, Bruker (Germany) with $\mathrm{CuK} \alpha$ radiation $(\lambda=1.5406 \AA)$. The morphology of the obtained sample was determined by scanning electron microscope (SEM) using SEM JMS5300LV (Japan). The specific surface area of the sample was determined by nitrogen adsorption/desorption isotherms using a Micromeritics 2020 volumetric adsorption analyzer system (USA). Thermal behaviors of the obtained materials were analyzed by means of thermal analysis (TG-DTA) using Labsys TG Setaram (France). The element analysis was conducted by atomic absorption spectrometry (AAS) using AA6800 Shimazu (Japan). Visible spectrophotometry was measured by Lambda 25 Spectrophotometer, PerkinElmer (Singapore) at $\lambda_{\max }$ of RDB dye $(600 \mathrm{~nm})$.

\section{Results and Discussion}

3.1. Characterization of ZIF-8 and Fe-ZIF-8. Figure 1 shows XRD patterns of ZIF-8 and Fe- ZIF-8. The XRD pattern of ZIF-8 in this work agreed well with patterns from [30, 31]. There was a well-defined diffraction (011) at two theta $=7.16^{\circ}$ in the XRD pattern of ZIF-8, indicating that the crystallinity of ZIF-8 in this work was relatively high. The XRD patterns of Fe-ZIF-8 also exhibited characteristic peaks of ZIF-8 and no

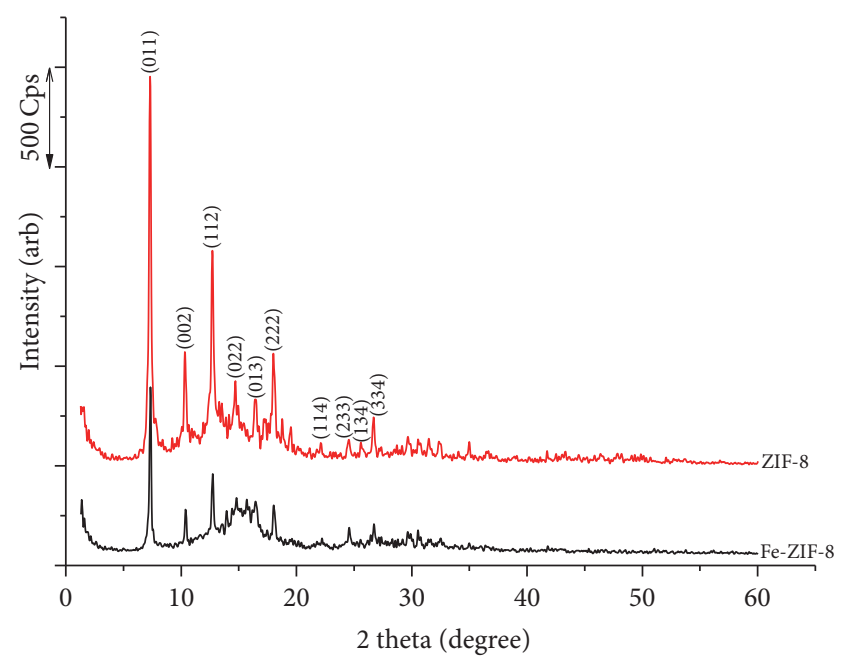

FIGURE 1: XRD patterns of ZIF-8 and Fe-ZIF-8.

characteristic peaks of iron oxides were observed. However, intensity of these diffractions decreases as a certain amount of iron was doped into the ZIF-8 framework.

SEM images of ZIF-8 and Fe-ZIF-8 are presented in Figure 2. Morphology of ZIF-8 consisted of spherical particles with a diameter around $100 \mathrm{~nm}$ while the irregular shapes of Fe-ZIF- 8 with sizes around $0.1-100 \mathrm{~nm}$ were observed. The introduction of iron into ZIF-8 caused a significant change in morphology of ZIF-8.

The zinc and iron compositions were analyzed by AAS. The results are presented in Table 1. Iron percentage in the final product $(0.116)$ was higher than the original $(0.100)$. The $\mathrm{pH}$ of the synthesized gel was around 4.5. Then iron(II) was likely to incorporate completely into ZIF-8; however, possibly $\mathrm{Zn}$ (II) was partly dissolved in the solution. This is reason why there was an increase in the percentage of iron in the final product.

The XPS spectra indicated a chemical state of element, that is, iron (Fe2p) and zinc ( $\mathrm{Zn} 2 \mathrm{p})$. The peak of $\mathrm{Zn}$ 2p1/2 (1044 eV) and Zn2p3/2 (1020.96 eV) observed for both samples confirmed the existence of $\mathrm{Zn}$ (II) (Figure 3). For ZIF-8, the peak of Fe 2p3/2 was inconspicuous, indicating that iron was a very minor component (in fact, it could not be detected). Only peak $\mathrm{Fe} 2 \mathrm{p} 3 / 2$ for Fe(II) at $709.98 \mathrm{eV}$ was detected implying the main iron in Fe-ZIF-8 was Fe(II). The percentage of oxidation state of iron, calculated from peak areas, was listed in Table 1. It was worth noting that the initial iron source of $\mathrm{Fe}(\mathrm{III})$ was also tested to incorporate into ZIF8 but the solid product was not obtained. This means that the presence of $\mathrm{Fe}$ (III) in the initial synthesized mixture was not favorable for the formation of ZIF-8 structure.

Based on ZIF-8 with space group of $I \overline{4} 3 m$ [52] the cell parameter of ZIF-8 and Fe-ZIF-8 was expressed by

$$
\frac{1}{d^{2}}=\frac{\left(h^{2}+k^{2}+l^{2}\right)}{a^{2}},
$$

where $d$ is spacing distance, $a$ is cell parameter, and $h, k, l$ are Miller indexes of diffraction planes. 


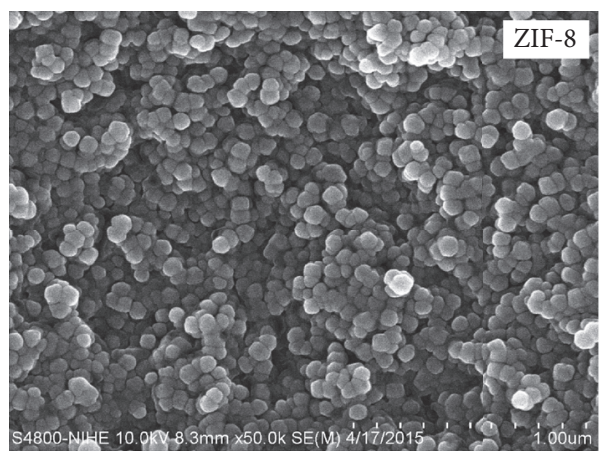

(a)

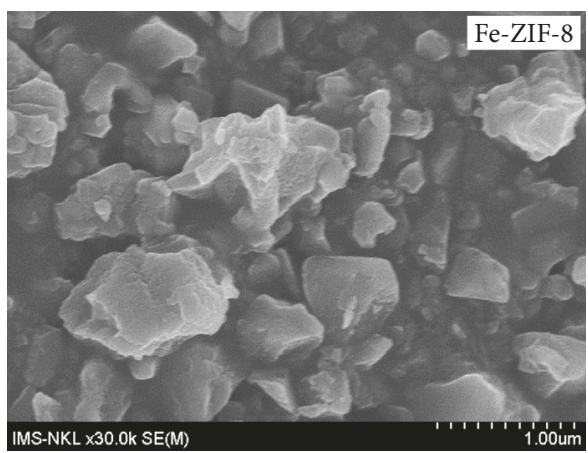

(b)

FIGURE 2: SEM observations of ZIF-8 and Fe-ZIF-8.

TABLE 1: Chemical composition of ZIF-8 and Fe-ZIF-8 analyzed by AAS and XPS.

\begin{tabular}{lcccccc}
\hline Adsorbent & $\begin{array}{c}\mathrm{Zn} \\
(\mathrm{mol} / \mathrm{g})\end{array}$ & $\begin{array}{c}\mathrm{Fe} \\
(\mathrm{mol} / \mathrm{g})\end{array}$ & $\begin{array}{c}\text { Molar ratio } \\
(\mathrm{Fe} /(\mathrm{Zn}+\mathrm{Fe}))\end{array}$ & $\begin{array}{c}\text { Initial molar ratio } \\
(\mathrm{Fe} /(\mathrm{Zn}+\mathrm{Fe}))\end{array}$ & $\begin{array}{c}\mathrm{Fe}(\mathrm{II}) \\
(\%)\end{array}$ & $\begin{array}{c}\text { XPS } \\
(\%)\end{array}$ \\
\hline ZIF-8 & 0.043 & - & 0 & - & - & - \\
Fe-ZIF-8 & 0.038 & 0.005 & 0.116 & 0.100 & 100 & 0.000 \\
\hline
\end{tabular}

TABLE 2: Textural properties of ZIF-8 andFe-ZIF-8.

\begin{tabular}{lcccc}
\hline Adsorbent & ${ }^{1} S_{\text {BET }}\left(\mathrm{m}^{2} / \mathrm{g}\right)$ & ${ }^{2} S_{\text {Langmuir }}\left(\mathrm{m}^{2} / \mathrm{g}\right)$ & ${ }^{3} D_{\text {pore }}(\mathrm{nm})$ & \\
\hline ZIF-8 & 1383 & 1909 & 3.34 & ${ }^{4} V_{\text {pore }}\left(\mathrm{cm}^{3} / \mathrm{g}\right)$ \\
Fe-ZIF-8 & 1243 & 1599 & 2.06 & 1.16 \\
\hline
\end{tabular}

${ }^{1} S_{\text {BET }}$ : specific surface area calculated by BET model; ${ }^{2} S_{\text {Langmuir }}:$ specific surface area calculated by Langmuir model; ${ }^{3} D_{\text {pore }}:$ pore diameter calculated by BJH model; ${ }^{4} V_{\text {pore }}$ : pore volume.

The cell parameter of ZIF-8 (16.800 $\AA$ ) and Fe-ZIF-8 (16.977 $\AA$ ) seems to be unchangeable. Since the charge and radii of $\mathrm{Zn}^{2+}(0.75 \AA)$ and $\mathrm{Fe}^{2+}(0.74 \AA)$ are similar, it is likely that $\mathrm{Fe}(\mathrm{II})$ can substitute $\mathrm{Zn}$ (II) in ZIF-8 or disperse highly in ferrous forms.

Figure 4 shows the nitrogen adsorption/desorption isotherms of ZIF-8 and Fe-ZIF-8. All samples exhibited type IV with $\mathrm{H} 4$ which is characteristic of mesoporous materials. Fe-ZIF-8 possessed a shape which is different from ZIF8 at high relative pressure. This result suggests that the porous structure was distorted due to the incorporation of iron oxides. ZIF-8 exhibited a high specific surface area of $1380 \mathrm{~m}^{2} \cdot \mathrm{g}^{-1}$ (calculated by BET model), which was similar to that found in the previous literature $[30,31,53]$.

The introduction of iron oxide into ZIF-8 lowered the specific surface area, the pore diameter, and the pore volume. The specific surface areas are 1380 and $1243 \mathrm{~m}^{2} \cdot \mathrm{g}^{1}$ for ZIF8 and Fe-ZIF-8, respectively (see Table 2). This also gave evidence of the encapsulation of iron oxides within the pores of framework, which brought about the lowering of accessible void space for $\mathrm{N}_{2}$ gas molecules.

The thermal stability of materials was tested by TG-DTA. ZIF- 8 and Fe-ZIF- 8 were found to be highly stable up to $220^{\circ} \mathrm{C}$ and $250^{\circ} \mathrm{C}$. Beyond this temperature the framework slowly started to decompose and a flat valley was obtained till $700^{\circ} \mathrm{C}$ (Figure 5). The incorporation of iron in ZIF-8 seems to make the materials more stable. This behavior was also observed as $\mathrm{TiO}_{2}$ is doped in ZIF-8 [54].

The stability of ZIF- 8 in water with different $\mathrm{pHs}$ was also studied. Figure 6 presents XRD patterns of ZIF- 8 which were soaked in water with $\mathrm{pH}$ from 2 to 12 . The $\mathrm{pH}$ of the solution was adjusted by $\mathrm{NaOH} 0.01 \mathrm{M}$ or $\mathrm{HCl} 0.01 \mathrm{M}$. The crystallinity of ZIF-8 nanoparticles was retained well at $\mathrm{pH}>3-12$, which proved that ZIF-8 was stable in aqueous solutions with $\mathrm{pHs}$ in the range of $3-12$.

\subsection{A Study on RDB Adsorption onto ZIF-8 and Fe-ZIF-8}

3.2.1. Effect of Initial RDB Concentration. The experimental results for adsorption at various concentrations $\left(30-50 \mathrm{mg} \cdot \mathrm{L}^{-1}\right)$ with contact time are shown in Figure 7 . As seen from Figure 7, the adsorption capacity of adsorbent increases as initial dye concentrations go up. The RDB adsorption of Fe-ZIF-8 was higher than that of ZIF-8 in the same initial concentration. The adsorption capacity of RDB onto ZIF-8 increased from 30.20 to $42.14 \mathrm{mg} \mathrm{g}^{-1}$ and that onto Fe-ZIF-8 increased from 50.36 to $76.79 \mathrm{mgg}^{-1}$ as the initial concentrations increased from 30 to $50 \mathrm{mg} \mathrm{g}^{-1}$. The initial dye concentration provided a critical driving force to overcome all the mass transfer resistance of RDB between 


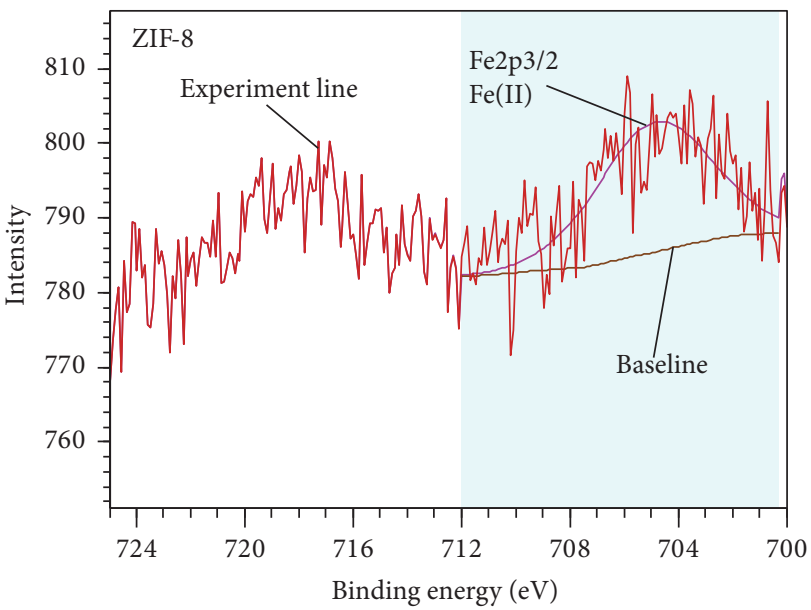

(a)

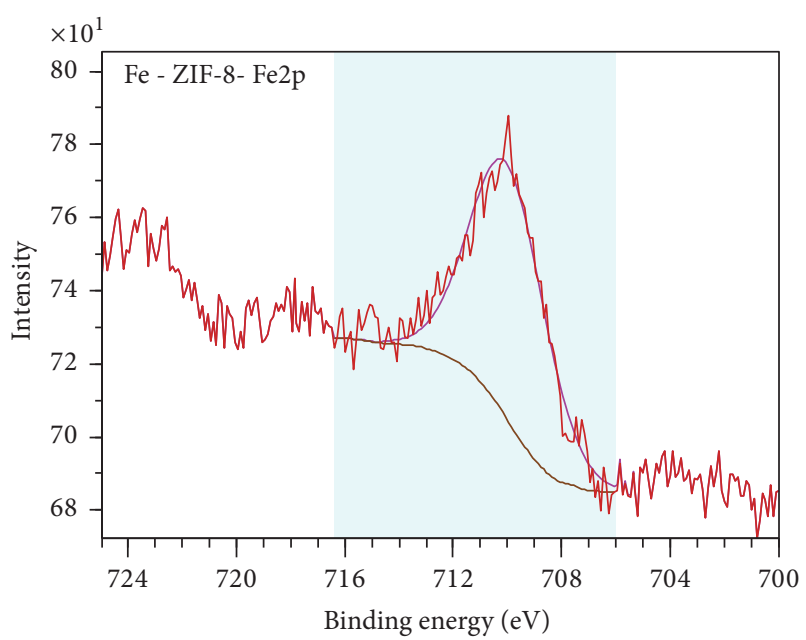

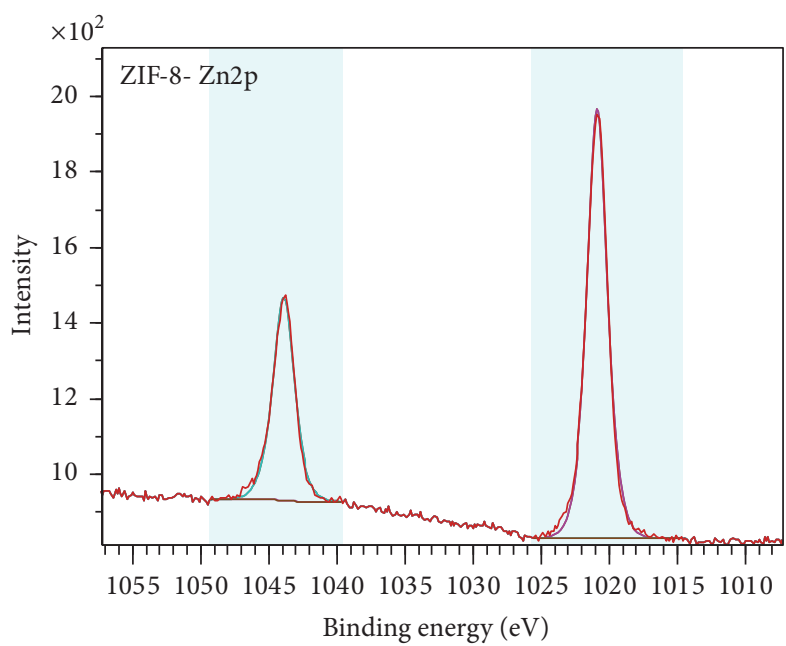

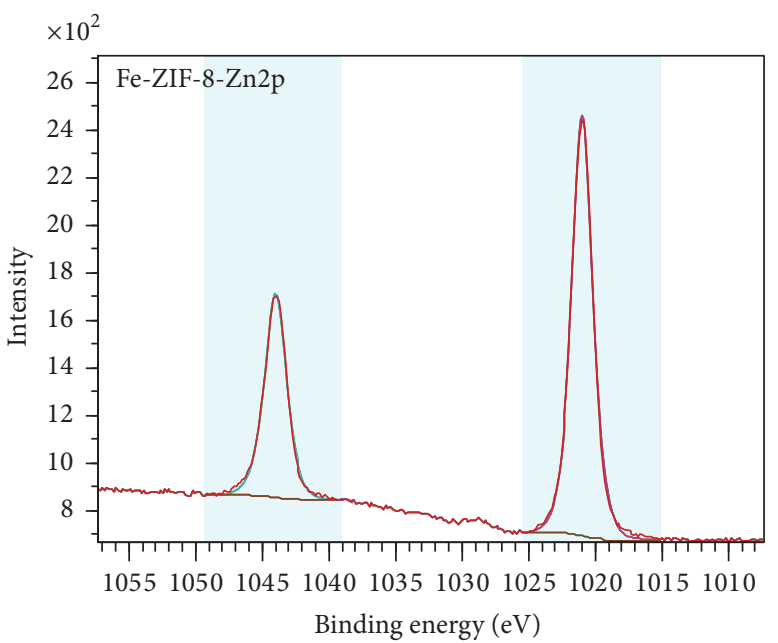

(b)

Figure 3: XPS Fe2p and Zn2p core level spectra of ZIF-8 (a) and Fe-ZIF-8 (b).

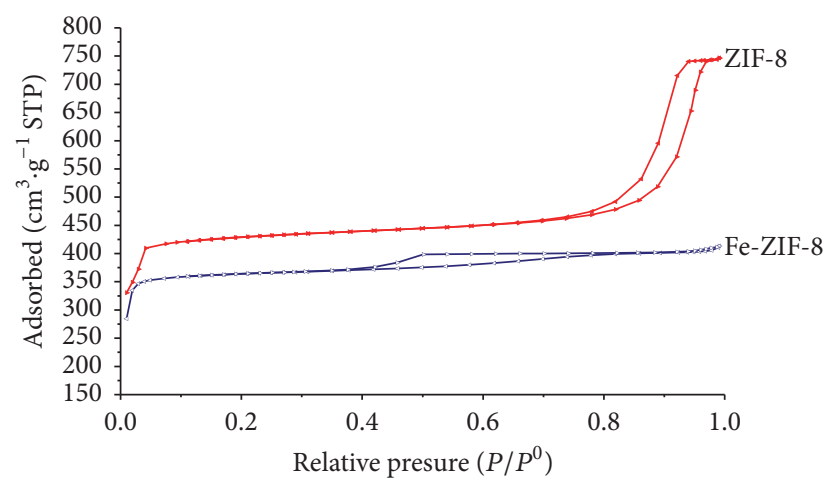

FIGURE 4: Nitrogen adsorption/desorption isotherms of ZIF-8 and Fe-ZIF-8.

the aqueous solution and the adsorbent surface [55]. As a result, high initial $\mathrm{RDB}$ concentration might promote the adsorption process. Figure 7 indicates that the adsorption of $\mathrm{RDB}$ was fast in the earlier stage (0-100 minutes) and gradually reached the equilibrium. It is found that the time required to obtain the adsorption equilibrium was around 250 minutes.

Due to the porosity of ZIF-8 and Fe-ZIF-8, intraparticle diffusion was expected in the adsorption process. This was examined by plotting RDB uptake, $q_{t}$ against the square root of time, $t^{1 / 2}$ as (6). If intraparticle diffusion is the rate-limiting step this plot will give a straight line and an intercept equal to zero. However, previous studies by various researchers showed that these plots represent multilinearity [56]. This application often suffers uncertainties caused by the multilinear nature of their plot. Therefore, the confidence intervals for parameters are determined to estimate their uncertainties. If the $95 \%$ confidence interval of $y$-intercept does not contain zero or it varies from this negative/positive value to another, $y$-intercept is significantly different from zero. It is concluded that the line does not pass through the origin or vice versa (in this study the SPSS-version 21 was used to calculate the confidence interval). 

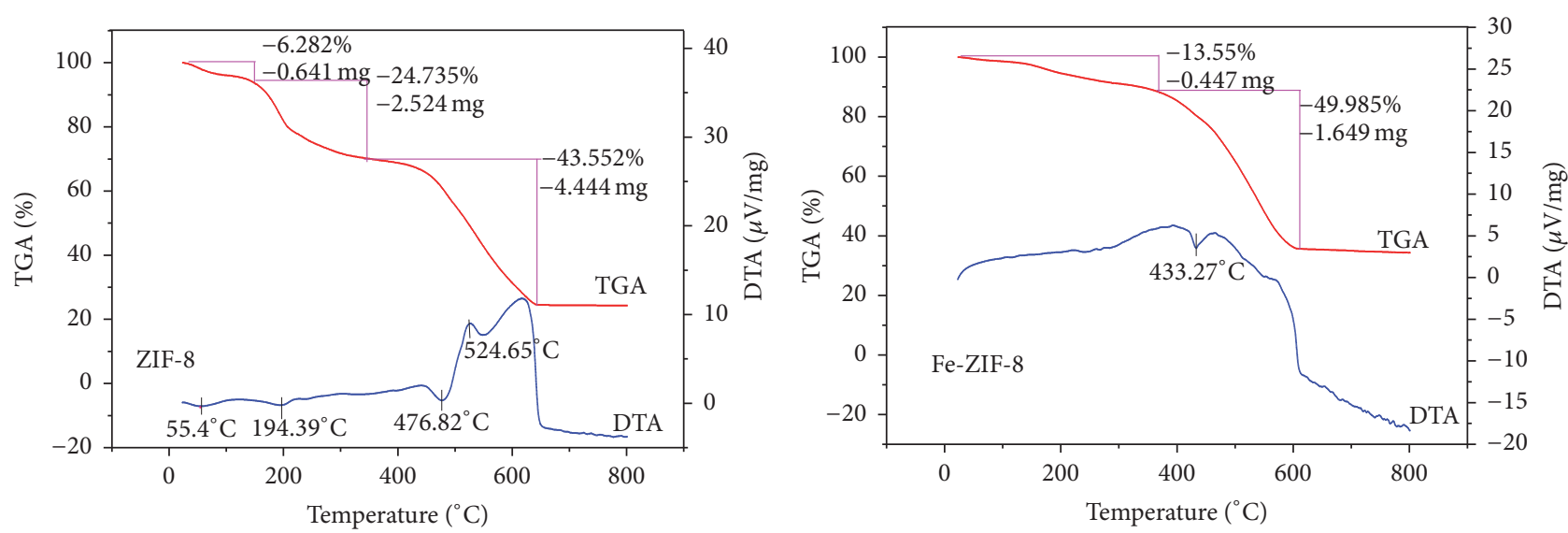

FIgURE 5: TGA-DTA of ZIF-8 and Fe-ZIF-8.

TABLE 3: Comparison of piecewise linear regression for one, two, and three linear segments by AIC.

\begin{tabular}{lccccccccccc}
\hline \multirow{2}{*}{ Adsorbent } & \multirow{2}{*}{$\begin{array}{c}C_{\mathrm{RDB}} \\
\mathrm{mg} \cdot \mathrm{L}^{-1}\end{array}$} & \multicolumn{2}{c}{ One linear segment's regression } & \multicolumn{2}{c}{ Two linear segments' regression } & \multicolumn{3}{c}{ Three linear segments' } \\
& & SSE & $R^{2}$ & AIC & SSE & $R^{2}$ & AIC & SSE & $R^{2}$ & AIC \\
\hline \multirow{3}{*}{ ZIF-8 } & 30 & 247.07 & 0.905 & 62.72 & 82.93 & 0.968 & 39.30 & 82.93 & 0.968 & 45.34 \\
& 40 & 736.84 & 0.858 & 91.13 & 189.35 & 0.964 & 60.77 & 189.35 & 0.964 & 66.78 \\
& 50 & 619.32 & 0.884 & 89.47 & 33.91 & 0.994 & 16.05 & 33.91 & 0.995 & 22.46 \\
\hline \multirow{3}{*}{ Fe-ZIF-8 } & 30 & 835.06 & 0.650 & 94.38 & 54.13 & 0.977 & 28.51 & 54.14 & 0.977 & 34.23 \\
& 40 & 2070.79 & 0.973 & 117.99 & 317.80 & 0.967 & 72.76 & 317.80 & 0.967 & 80.24 \\
& 50 & 984.31 & 0.846 & 98.65 & 23.73 & 0.996 & 6.77 & 21.33 & 0.997 & 10.01 \\
\hline
\end{tabular}

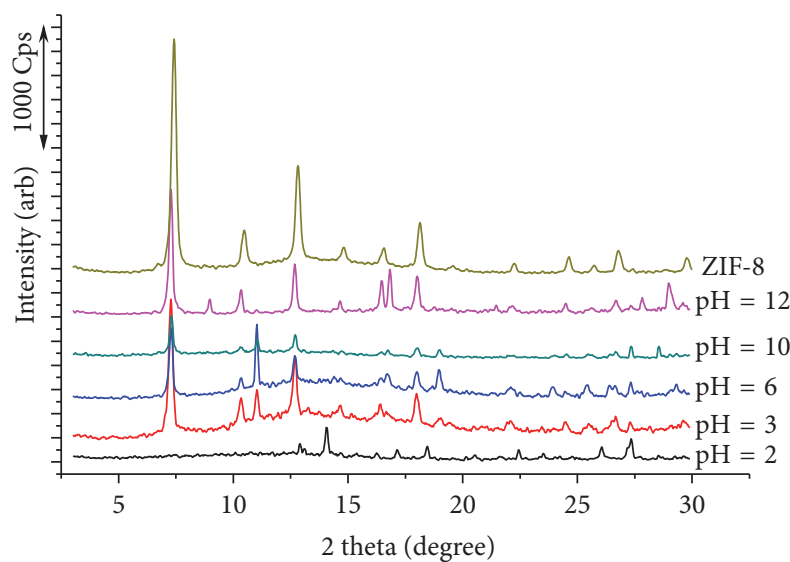

FIGURE 6: XRD diffraction patterns of the ZIF-8 soaked in water with different $\mathrm{pHs}\left(m_{\mathrm{ZIF}-8} / V_{\text {solution }}=0.1 \mathrm{~g} / 30 \mathrm{ml}, \mathrm{pH}=2-12\right.$; socking time: 24 hours).

Piecewise linear regression proposed by Malash and El-Khaiary [38] was applied to analyze multilinearity of Webber's plot. Since increasing the number of linear segments leads to an increase in the number of regression parameters, a decrease in $\mathrm{SSE}_{T}$ naturally follows. For this reason, $\mathrm{SSE}_{T}$ solely cannot be used to assess the goodness of fit for models. The well-known statistical method for model comparison is Akaike's Information Criterion (AIC) [38, 57]. This method advises which model is more likely to be correct. The smaller
AIC value indicates a more compatible model. For example, Figure 8 illustrates experimental data and piecewise linear regression lines with initial concentration $50 \mathrm{mg} \mathrm{L}^{-1}$ for ZIF8 and Fe-ZIF-8. The experimental points seem to be close to regression lines for two or three linear segment lines. We could not estimate visually which one is more likely correct. The values of $\mathrm{AIC}_{\mathrm{c}}$ for $\mathrm{RDB}$ adsorption onto ZIF8 are 89.47 and 16.05 and 22.46 for one-segment, twosegment, and three-segment models, respectively. Those for RDB adsorption onto Fe-ZIF-8 are 98.65 and 6.67 and 10.01 for one-segment, two-segment, and three-segment models, respectively. It is decided to accept the model with two linear segments as the correct model because of the lowest value of $\mathrm{AIC}_{\mathrm{c}}$ in this model.

A comparison of models based on $\mathrm{AIC}_{\mathrm{c}}$ is presented in Table 3. Table 3 shows that Webber's model analyzed two segments linear regression provided the lowest $\mathrm{AIC}_{\mathrm{c}}$ compared to one- or three-segment models. In conclusion, the experimental data best fit with the two segments' linear regression model. Results of piecewise two linear segments' regression for different initial concentrations are shown in Table 4. For illustration, for $50 \mathrm{mg} \mathrm{L}^{-1}$ concentration of ZIF-8 in Figure 8, the intercepts of the first line in the Webber plot were -10.19 with $95 \%$ confidence interval $(-12.28$ to -8.10$)$. This value of the intercept was significantly different from zero. It means the line did not pass through the origin. The similar behaviors were observed for all the other cases. These results indicate that the adsorption of RDB dye onto ZIF-8 

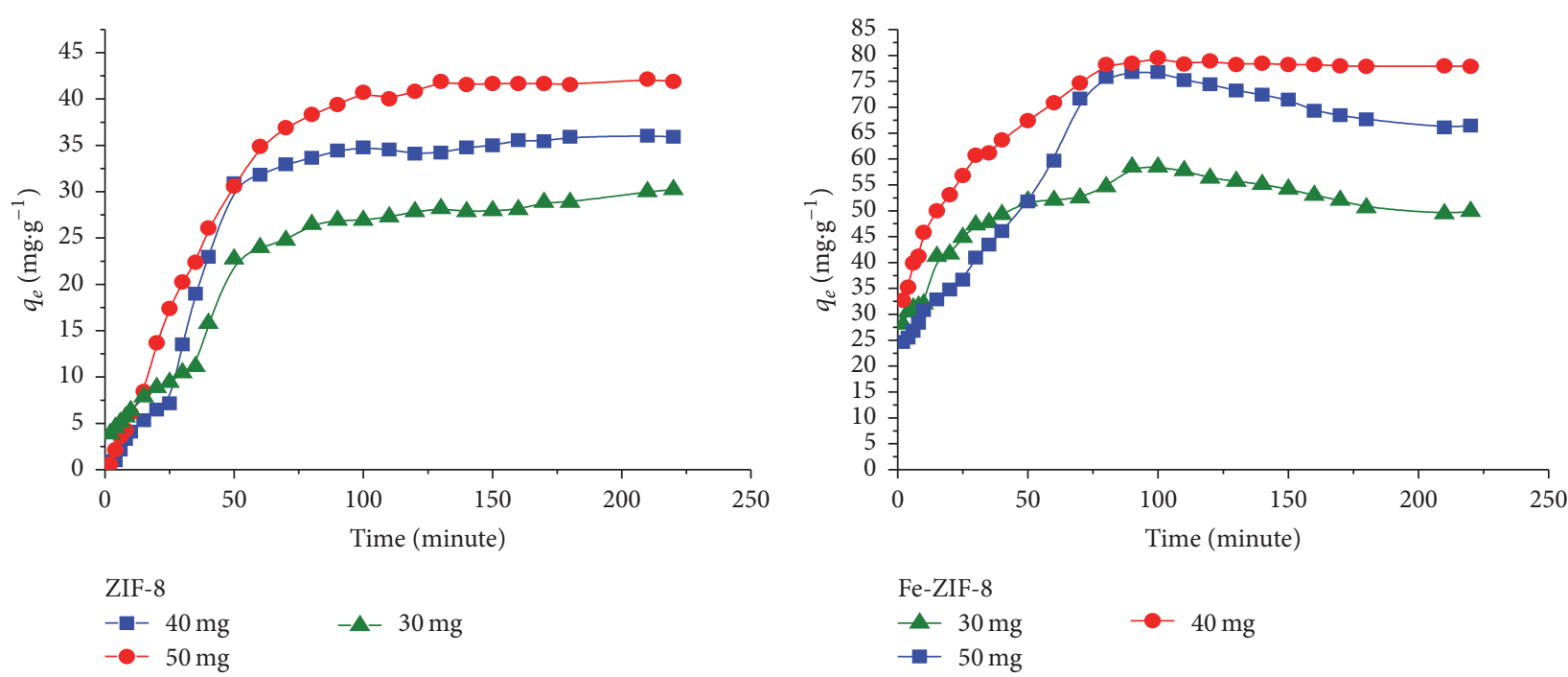

Figure 7: Effect of contact time on the adsorption of RDB by ZIF- 8 and Fe-ZIF- $8\left(C_{\mathrm{RDB}}=30-50 \mathrm{mg} \cdot \mathrm{L}^{-1}\right.$, adsorbent $=0.2 \mathrm{~g}$, and initial $\mathrm{pH}=$ $8.2 ; V_{\mathrm{RDB}}=500 \mathrm{ml}$, temperature $=30^{\circ} \mathrm{C}$, and stirring rate $\left.=500 \mathrm{rpm}\right)$.

TABLE 4: Results of piecewise regression for the two linear segments for ZIF-8 and Fe-ZIF-8 (the values in parentheses are at a 95\% confidence level).

\begin{tabular}{|c|c|c|c|c|c|c|}
\hline \multirow{2}{*}{ Adsorbent } & \multirow{2}{*}{$\begin{array}{l}\text { Concentration } \\
\left(\mathrm{mg} \cdot \mathrm{L}^{-1}\right)\end{array}$} & \multirow{2}{*}{$\begin{array}{l}\text { Break point } \\
\left(\text { minute }^{0.5}\right)\end{array}$} & \multicolumn{2}{|c|}{ The first linear segment } & \multicolumn{2}{|c|}{ The second linear segment } \\
\hline & & & Intercept 1 & Slope 1 & Intercept 2 & Slope 2 \\
\hline \multirow{3}{*}{ ZIF-8 } & 30 & 5.92 & $\begin{array}{c}-2.83 \\
(-5.11:-0.55)\end{array}$ & 4.68 & $\begin{array}{c}19.16 \\
(17.58: 20.74)\end{array}$ & 0.75 \\
\hline & 40 & 7.07 & $\begin{array}{c}-10.29 \\
(-17.10:-3.47)\end{array}$ & 4.83 & $\begin{array}{c}27.06 \\
(25.29: 28.83)\end{array}$ & 0.67 \\
\hline & 50 & 8.94 & $\begin{array}{c}-10.19 \\
(-12.28:-8.10) \\
\end{array}$ & 5.58 & $\begin{array}{c}34.85 \\
(32.21: 37.49) \\
\end{array}$ & 0.52 \\
\hline \multirow{3}{*}{ Fe-ZIF-8 } & 30 & 9.49 & $\begin{array}{c}22.58 \\
(20.16: 25.00)\end{array}$ & 3.85 & $\begin{array}{c}78.07 \\
(75.00: 81.15)\end{array}$ & -1.97 \\
\hline & 40 & 10.00 & $\begin{array}{c}8.13 \\
(2.64: 13.63)\end{array}$ & 6.82 & $\begin{array}{c}98.79 \\
(93.99: 103.59)\end{array}$ & -2.26 \\
\hline & 50 & 8.94 & $\begin{array}{c}25.38 \\
(23.59: 27.16)\end{array}$ & 6.01 & $\begin{array}{c}80.15 \\
(78.58: 81.72)\end{array}$ & -0.15 \\
\hline
\end{tabular}

or Fe-ZIF-8 in the first stage was controlled by film diffusion (e.g., surface adsorption and liquid film diffusion) while the second was assigned to intraparticle diffusion [57-59]. The breakpoints (see Table 4) reflect the adsorption process moving from one mechanism to another. The times of phase transition calculated by the square of breakpoints varied from 36 to 100 minutes. The adsorption could be divided into two distinct phases by the time of phase transition: (i) main adsorption of RDB molecules within 0-100 minutes of the contact times: this process was rather slow compared to other adsorbents $[40,57]$ in which the fast and instantaneous adsorption was observed; since the pore sizes of Fe-ZIF-8 or ZIF- 8 are around $1 \mathrm{~nm}$ [45], the adsorption of RDB with four benzene rings in which each has a critical dimension of around $0.662 \mathrm{~nm}$ [60] on ZIF-8 limited the diffusion of the RDB molecule to the inner pore structure; however, abundant active adsorption sites could be obtained at its external surface, which is helpful to the adsorption of dye molecules; (ii) a gradual attainment of the equilibrium where only about $5-10 \%$ of the adsorption was encountered. This is due to the utilization of the all active sites on the adsorbent surface. The first linear segment indicated a boundary layer effect while the second linear segment was assigned to intraparticle diffusion $[58,59]$.

The rate parameter, $k_{p}$, increases with an increase in initial concentrations. However, the effect of initial RDB on rate parameters was irregular for $\mathrm{RDB}$ adsorption onto $\mathrm{Fe}$ ZIF-8. The irregularity of $k_{p}$ could be related to that fact that iron incorporated caused the heterogeneity of ZIF-8 structure.

The experimental data usually exhibit the multilinear plots, two or more stages influencing the adsorption process. In the statistical method, the piecewise linear regression is relevant to analyzing the data with multilinearity instead of 

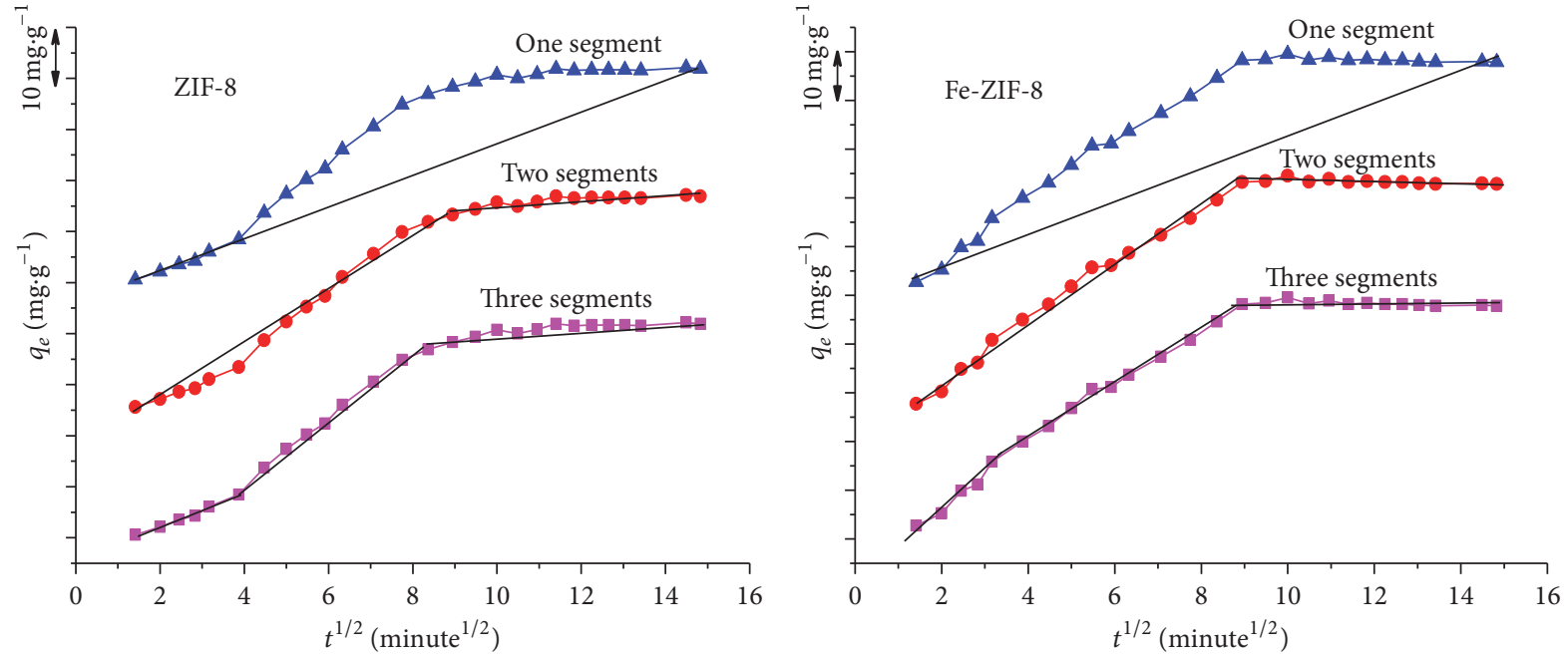

FIGURE 8: Plot of piecewise linear regression for one, two, and three segments' based Webber's model $\left(C_{\mathrm{RDB}}=50 \mathrm{mg} \cdot \mathrm{L}^{-1} ; m_{\mathrm{adsorbent}}=0.2 \mathrm{~g} ; \mathrm{V}\right.$ $=500 \mathrm{~mL}$; temperature $=30^{\circ} \mathrm{C}$; stirring rate $=500 \mathrm{rpm}$ ).

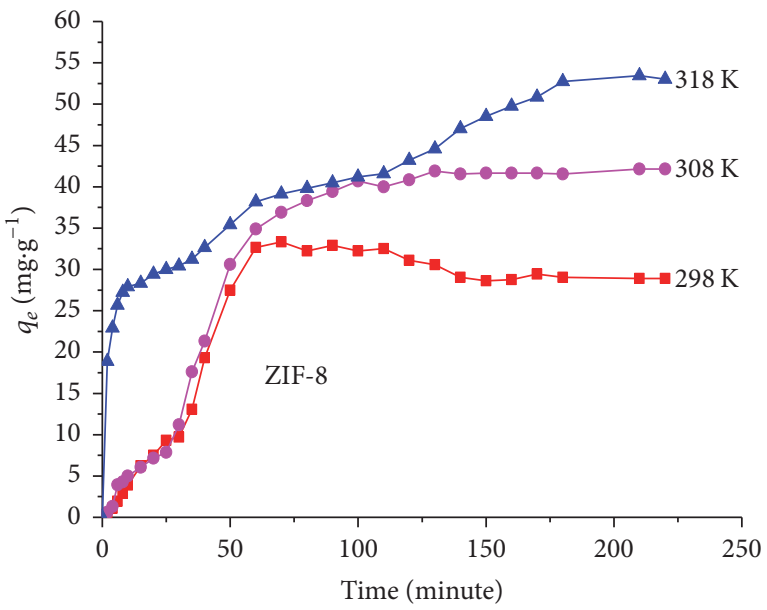

(a)

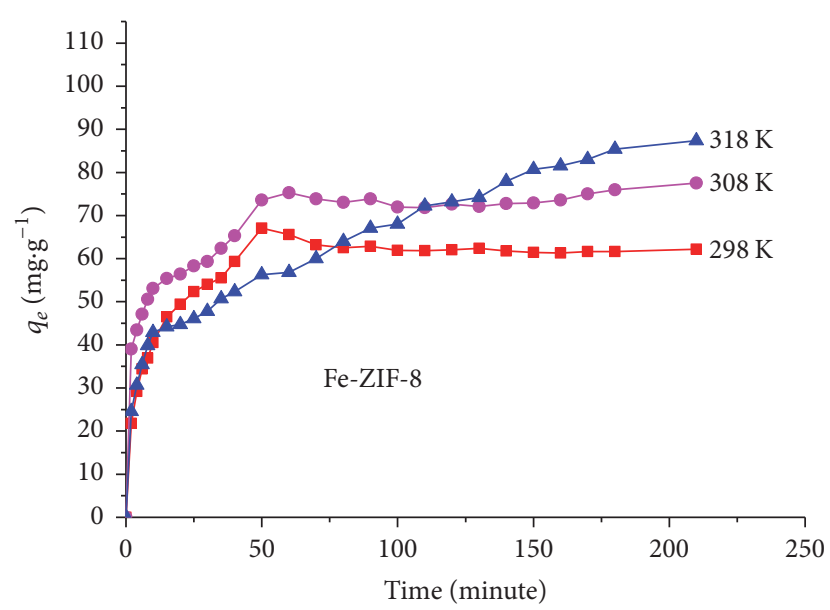

(b)

FIGURE 9: Effect of temperature on adsorption of RDB dye onto ZIF-8 (a) and Fe-ZIF-8 (b) $\left(C_{\mathrm{RDB}}=30-50 \mathrm{mg} \cdot \mathrm{L}^{-1}, m_{\mathrm{ZIF}-8}=0.2 \mathrm{~g}, V_{\mathrm{RDB}}=\right.$ $500 \mathrm{ml}$, and stirring rate: $500 \mathrm{ppm})$.

the conventional graphical analysis [61] that might misidentify objective break points or numbers of segments.

As seen from Figure 9, a possible desorption might occur where the RDB uptake appears to fluctuate or even drop a little. This behavior could be attributed to either a reversible adsorption or a back diffusion controlling mechanism [62]. The pseudo-first- or second-order kinetic models of Lagergren [33] or Ho and McKay [63], respectively, have been widely used to investigate the formal kinetics of adsorption processes [12, 27, 40, 64]. However, the present experimental data could not apply to these models due to reversible adsorption. In the present study, the pseudofirst-order kinetics model of Natarajan-Khalaf was used to analyze the experimental data. The rate constant, $k_{\text {ads }}$, for the adsorption of dye was determined from the slope of Natarajan-Khalaf's plots. The results are listed in Table 5. The high coefficient of determination $R^{2}(0.973-0.998)$ implies that this model was compatible with the experimental data. The rate constant of adsorption is separated into the rate of forward and reverse adsorption. The rate constants for the forward and reverse process are also presented in Table 5. It is clear that the adsorption kinetics can be significantly improved by the introduction of iron into the ZIF-8. As shown in Table 5 the rate constants for adsorption could be increased approximately 5 times by Fe-ZIF- 8 and the kinetics with Fe-ZIF-8 were faster than that with ZIF-8.

Adsorption thermodynamics was conducted by varying the temperature from $298 \mathrm{~K}$ to $318 \mathrm{~K}$ as shown in Figure 9.

The thermodynamic parameters including activation energy, $K_{\text {eq }}, k_{1}$, and $k_{2}$ are presented in Table 6 . The results showed that equilibrium adsorption capacity, $q_{\text {eq }}$, of both adsorbents increased with an increase in temperature which indicated that the process was endothermic. The equilibrium adsorption capacity of Fe-ZIF-8 is higher than that of ZIF-8 
TABLE 5: Rate constants for the adsorption and the rate constants for the forward and reverse process and equilibrium constants at different concentrations for ZIF-8 and Fe-ZIF-8.

\begin{tabular}{lcccccc}
\hline Adsorbent & $\begin{array}{c}C_{\mathrm{RDB}} \\
(\mathrm{mg} / \mathrm{L})\end{array}$ & $k_{\mathrm{ads}}$ & $k_{1}$ & $k_{2}$ & $K_{o}$ & 0.995 \\
\hline \multirow{2}{*}{ ZIF-8 } & 30 & 0.0023 & 0.0009 & 0.0014 & 0.6429 & 0.5625 \\
& 40 & 0.0025 & 0.0009 & 0.0016 & 0.4839 & 0.990 \\
\hline \multirow{3}{*}{ Fe-ZIF-8 } & 50 & 0.0046 & 0.0015 & 0.0031 & 0.0038 & 0.991 \\
& 30 & 0.0115 & 0.0077 & 0.0041 & 0.993 \\
& 40 & 0.0122 & 0.0081 & 0.0071 & 1.5915 & 0.980 \\
\hline
\end{tabular}

TABLE 6: Activation energy, equilibrium and rate constants for RDB dye adsorption, and rate constants for forward and reverse process of RDB adsorption onto ZIF-8 and Fe-ZIF-8.

\begin{tabular}{|c|c|c|c|c|c|c|c|c|c|}
\hline Absorbent & $\begin{array}{l}\text { Temp. } \\
(K)\end{array}$ & $K_{\mathrm{eq}}$ & $\begin{array}{c}q_{\mathrm{eq}} \\
\left(\mathrm{mg}^{-1} \mathrm{~g}^{-1}\right)\end{array}$ & $\begin{array}{c}k_{1} \\
\left(\times 10^{3}\right) \\
\left(\min ^{-1}\right)\end{array}$ & $\begin{array}{c}k_{2} \\
\left(\times 10^{3}\right) \\
\left(\min ^{-1}\right)\end{array}$ & $\begin{array}{c}k_{\mathrm{ads}} \\
\left(\times 10^{3}\right) \\
\left(\min ^{-1}\right)\end{array}$ & $R^{2}$ & $\begin{array}{c}E_{a} \\
\left(\mathrm{~kJ} \cdot \mathrm{mol}^{-1}\right)\end{array}$ & $R^{2}$ \\
\hline \multirow{3}{*}{ ZIF-8 } & 298 & 1.272 & 28.89 & 0.890 & 1.800 & 2.700 & 0.990 & 48.270 & 0.991 \\
\hline & 308 & 1.570 & 43.94 & 1.914 & 2.692 & 4.606 & 0.988 & & \\
\hline & 318 & 1.842 & 53.02 & 3.908 & 5.304 & 9.212 & 0.973 & & \\
\hline \multirow{3}{*}{ Fe-ZIF-8 } & 298 & 3.401 & 62.92 & 11.361 & 7.063 & 18.424 & 0.988 & 12.507 & 0.972 \\
\hline & 308 & 4.079 & 77.50 & 12.851 & 7.876 & 20.727 & 0.994 & & \\
\hline & 318 & 5.864 & 87.64 & 17.761 & 7.572 & 25.333 & 0.991 & & \\
\hline
\end{tabular}

TABLE 7: Activation parameters for RDB dye adsorption onto ZIF-8 and Fe-ZIF-8.

\begin{tabular}{|c|c|c|c|c|c|}
\hline Adsorbent & $\begin{array}{c}\text { Temperature } \\
(\mathrm{K})\end{array}$ & $\begin{array}{c}\Delta S^{\#} \\
\left(\mathrm{~J} \cdot \mathrm{mol}^{-1} \cdot \mathrm{K}^{-1}\right)\end{array}$ & $\begin{array}{c}\Delta H^{\#} \\
\left(\mathrm{~kJ} \cdot \mathrm{mol}^{-1}\right)\end{array}$ & $\begin{array}{c}\Delta G^{\#} \\
\left(\mathrm{~kJ} \cdot \mathrm{mol}^{-1}\right)\end{array}$ & $R^{2}$ \\
\hline \multirow{3}{*}{ ZIF-8 } & 298 & -29.44 & 52.03 & 60.80 & 0.999 \\
\hline & 308 & & & 61.10 & \\
\hline & 318 & & & 61.39 & \\
\hline \multirow{3}{*}{ Fe-ZIF-8 } & 298 & -153.40 & 9.94 & 55.66 & 0.960 \\
\hline & 308 & & & 57.19 & \\
\hline & 318 & & & 58.73 & \\
\hline
\end{tabular}

for each corresponding temperature. The increasing rate constant with an increase in temperature suggests that temperature favors the adsorption process for the fast rate to proceed. The equilibrium constant, $K_{\text {eq }}$, for Fe-ZIF- 8 and ZIF-8 changed in the range of 1.3-1.8 and 3.4-5.7, respectively, as temperature varied from 298 to $318 \mathrm{~K}$. It is worth noting that $K_{\mathrm{eq}}$ in the case of Fe-ZIF-8 is higher and increases much faster than that in the case of ZIF-8. The activation energy refers to the minimum amount of energy that must be overcome to proceed with the adsorption. $E_{a}$ for ZIF-8 and Fe-ZIF-8 was $48.27 \mathrm{~kJ}$ and $12.51 \mathrm{~kJ}$, respectively. Lower $E_{a}$ for Fe-ZIF-8 indicated that Fe-ZIF-8 was more favorable for RDB adsorption than ZIF-8. Low activation energy (below $42 \mathrm{~kJ} \mathrm{~mol}^{-1}$ ) implies diffusion controlled process because the temperature dependence of pore diffusivity is relatively weak and the diffusion process refers to the movement of the solute to an external surface and not diffusivity of material along microspore surfaces in a particle [65]. $E_{a}$ with ZIF8 is slightly higher than $42 \mathrm{~kJ} \mathrm{~mol}^{-1}$. However, a reversible adsorption was observed as shown in Figure 9, indicating that the rate-limiting step in this case involved a physicalchemical mechanism and not purely physical or chemical one. Therefore the RDB adsorption onto ZIF- 8 was also considered a diffusion controlled process and so is the RDB adsorption onto Fe-ZIF-8.

The activation parameters calculated using Eyring equation are presented in Table 7. This would express whether the adsorption process follows an active complex prior to the final sorption. The coefficient of determination was high for both ZIF-8 and Fe-ZIF-8 although the Eyring equation is not strictly linear with respect to $1 / T$ [66]. The negative value of $\Delta S^{*}\left(-29.44 \mathrm{~J} \mathrm{~K}^{-1} \mathrm{~mol}^{-1}\right.$ for ZIF-8 and $-153.40 \mathrm{~J} \mathrm{~K}^{-1} \cdot \mathrm{mol}^{-1}$ for Fe-ZIF-8) suggests a possibility of an associative chemisorption through the formation of an activated complex between RDB molecule and adsorbent [47], [63]. Also the negative value of $\Delta S^{\#}$ normally reflects that no significant change occurs in the internal structure of the adsorbent during the adsorption process $[41,66]$. The values for $\Delta H^{\#}$ (52.03 kJ.mol ${ }^{-1}$ for ZIF-8 and 9.94 for Fe-ZIF8 ) suggest that these reactions are endothermic. The large, 
TABLE 8: Thermodynamic parameters for the adsorption of RDB dye onto ZIF-8 and Fe-ZIF-8.

\begin{tabular}{|c|c|c|c|c|c|c|}
\hline \multirow{2}{*}{ Absorbent } & \multicolumn{3}{|c|}{$\Delta G^{0}(\mathrm{~kJ})$} & \multirow{2}{*}{$\Delta H^{0}(\mathrm{~kJ})$} & \multirow{2}{*}{$\Delta S^{0}(\mathrm{~J})$} & \multirow{2}{*}{$R^{2}$} \\
\hline & $298 \mathrm{~K}$ & $308 \mathrm{~K}$ & $318 \mathrm{~K}$ & & & \\
\hline ZIF-8 & -0.599 & -1.359 & -1.615 & 16.033 & 55.795 & 0.983 \\
\hline Fe-ZIF-8 & -1.092 & -3.600 & -4.677 & 51.639 & 170.000 & 0.980 \\
\hline
\end{tabular}

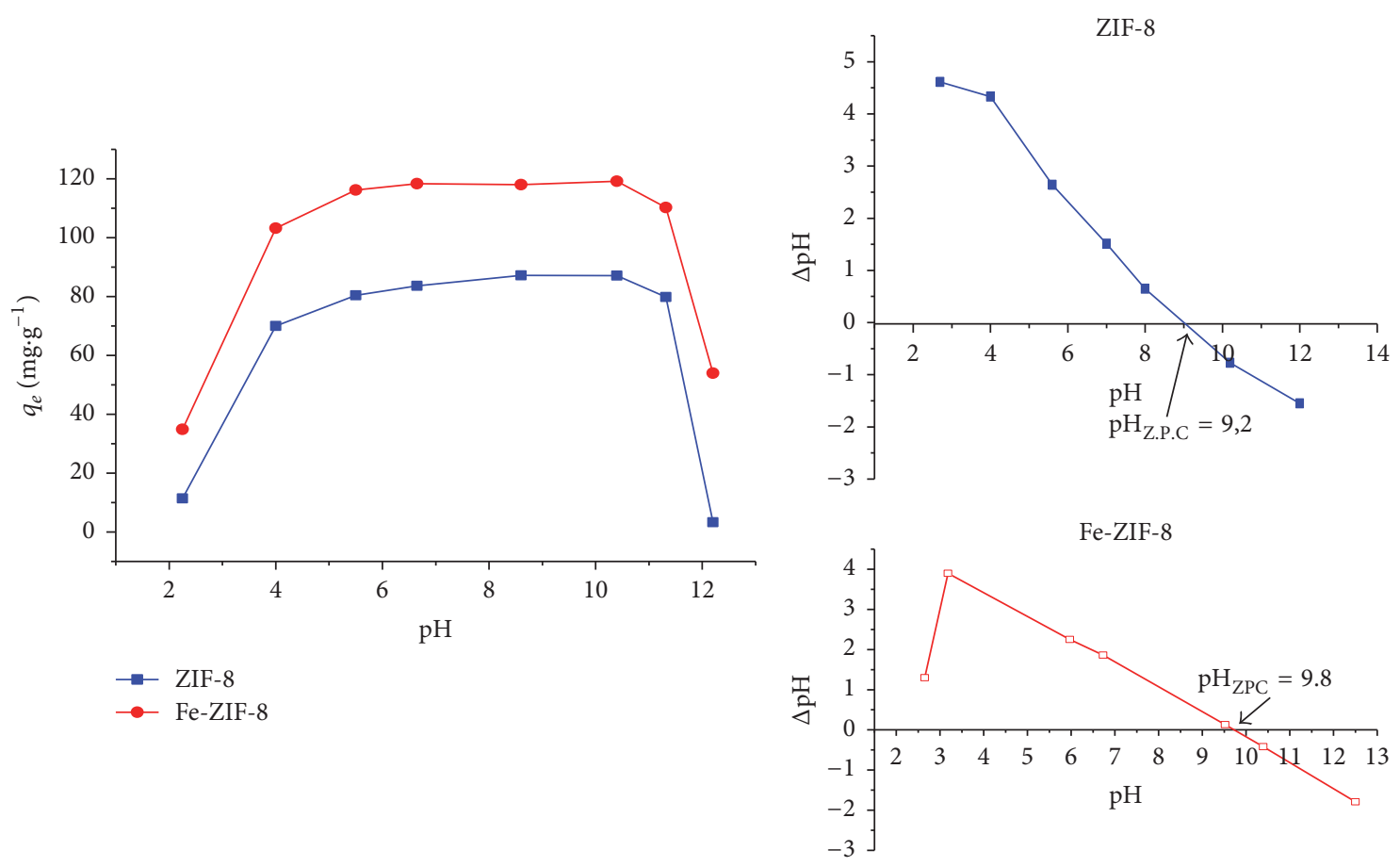

FIGURE 10: Effect of $\mathrm{pH}$ on the adsorption of RDB by ZIF-8 and Fe-ZIF-8 $\left(C_{\mathrm{RDB}}=50 \mathrm{mg} \cdot \mathrm{L}^{-1} ; m_{\text {Adsorbent }}=0.02 \mathrm{~g} ; \mathrm{V}=50 \mathrm{~mL}\right.$; shaking time $=$ $24 \mathrm{~h}$; Temp. $=30^{\circ} \mathrm{C}$ ).

positive $\Delta G^{\#}$ in both RDB adsorptions onto ZIF-8 and FeZIF-8 imply that these reactions require energy to convert reactants to the product and as the energy requirement is satisfied the reaction proceeds. Typically, $\Delta G^{\#}$ value relates to the adsorption rate. The rate increases as $\Delta G^{\#}$ decreases $[41,42]$. This is seen when comparing the data from Tables 6 and 7 . In Table 6 , the rate constant, $k_{\text {ads }}$, of Fe-ZIF- 8 is higher than that of ZIF-8. Table 7 describes the trend for $\Delta G^{\#}$ in which the Fe-ZIF-8 has the lower $\Delta H^{\#}$ value than ZIF-8.

The thermodynamic parameters, $\Delta H^{0}, \Delta S^{0}$, and $\Delta G^{0}$, of system were determined using van't Hoff equation to assess the spontaneity of adsorption process. In Table 8 , the results show that the adsorption process using ZIF-8 and Fe-ZIF- 8 was endothermic as indicated by the positive sign of the $\Delta H^{0}$ value. The positive value of $\Delta S^{0}$ indicates the increasing randomness at the solid-liquid interface during the adsorption of RDB molecules on the adsorbent [43]. The negative values of $\Delta G^{0}$ suggest the spontaneous RDB adsorption of RDB on ZIF-8 or Fe-ZIF-8. The more negative value at higher temperatures implies that the spontaneity increases with a temperature increase. As the Gibbs free energy change is negative and accompanied by the positive standard entropy change, the adsorption reaction is spontaneous with high affinity. Consistent with the findings in the kinetics, more negative values of $\Delta G^{0}$ with Fe-ZIF-8 were obtained compared to that with ZIF-8. Again, this confirmed the important role of iron in ZIF-8 in enhancing the RDB capacity.

3.2.2. Effect of $p H$. One of the important parameters controlling the adsorption process is $\mathrm{pH}$. Figure 10 shows the effect of $\mathrm{pH}$ on the removal of $\mathrm{RBB}$ dye from aqueous solutions. The behaviors of $\mathrm{pH}$ effect for RDB adsorption onto ZIF-8 and FeZIF-8 were similar. However, the RDB adsorption capacity of Fe-ZIF-8 was higher than that of ZIF-8. In general, the RDB adsorption capacity of adsorbents was observed to increase significantly with an increase in $\mathrm{pH}$ from 2.2 to 6 , followed by a slight increase in $\mathrm{pH}$ from 6 to 10 and it decreased significantly in further $\mathrm{pH}$ increase. The values of $\mathrm{pH}_{\mathrm{ZPC}}$ for ZIF-8 and Fe-ZIF-8 determined by $\mathrm{pH}$ drift method were around 9.2 and 9.8, respectively, and are in accordance with previous results [25, 27, 67] (the inset in Figure 10). The value of $\mathrm{pH}_{\mathrm{ZPC}}$ indicates that the surface of the adsorbent is positively charged when $\mathrm{pH}$ of the solution is below $\mathrm{pH}_{\mathrm{ZPC}}$, while the surface of adsorbent becomes negatively charged at $\mathrm{pH}$ of the solution above $\mathrm{pH}_{\mathrm{ZPC}}$. 


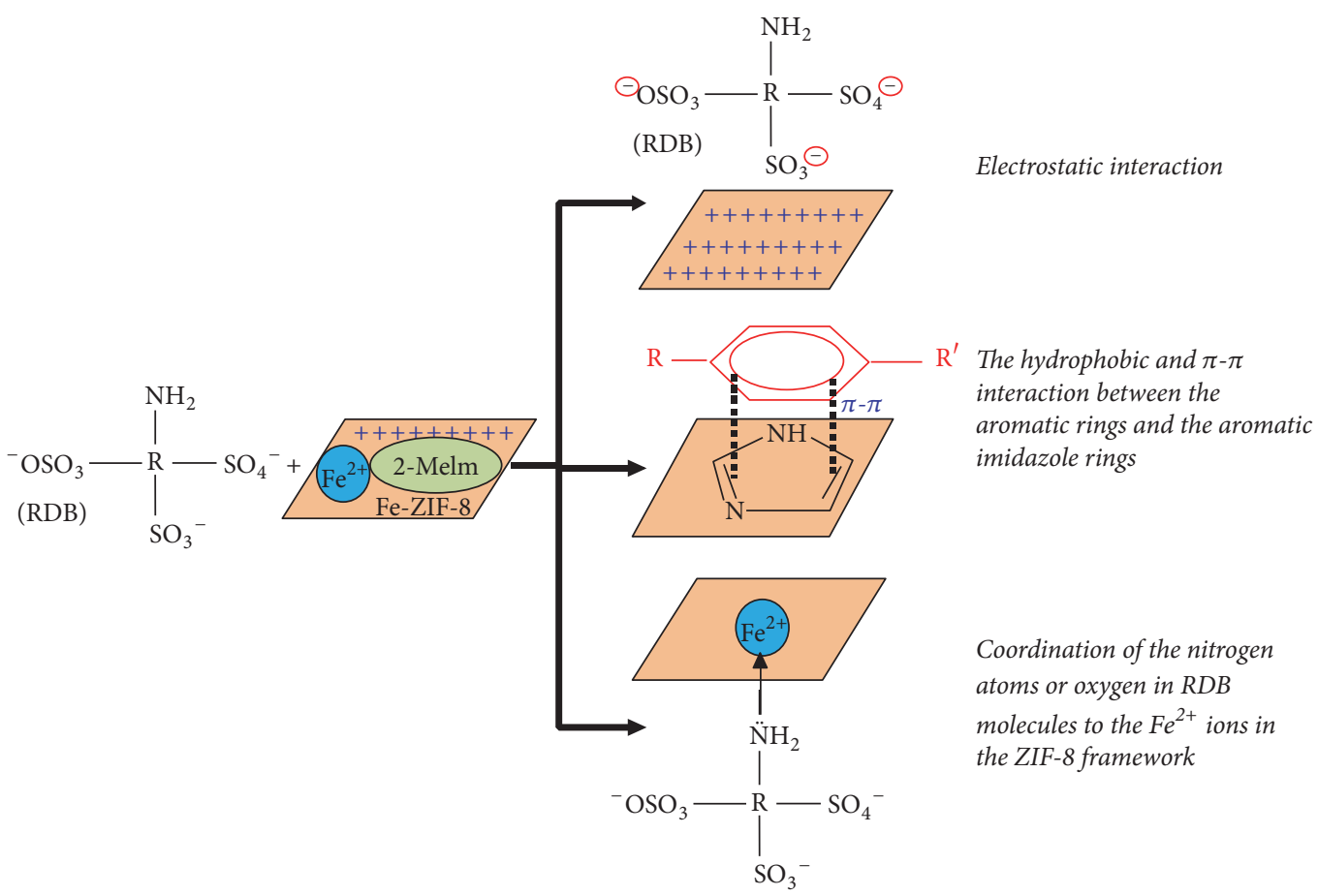

FIGURE 11: The proposed mechanism of RDB adsorption onto ZIF-8 or Fe-ZIF-8 at $\mathrm{pH}<\mathrm{pH}_{\mathrm{ZPC}}$. 2-Melm: 2-methylimidazole.

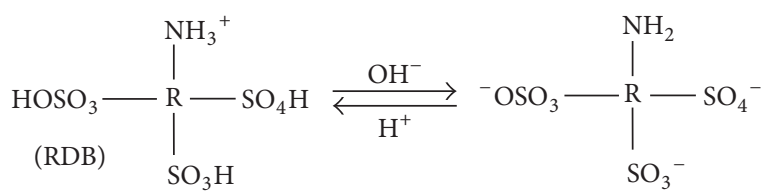

Scheme 2: Equilibrium of RDB in water.

As seen in Scheme 1, molecular structure of RDB consists of two groups of $-\mathrm{SO}_{3}{ }^{-}$and $-\mathrm{SO}_{4}{ }^{-}$, a group of $\mathrm{NH}_{2}$. Commonly, equilibrium of RDB in water is expressed as in Scheme 2.

Therefore, the higher $\mathrm{pH}$ is the more the equilibrium of (22) shifts to the right. With regard to the correlation of the electronic charges of the adsorbent/adsorbate and solution $\mathrm{pH}$ values, it can be presumed that there might be an electrostatic interaction between the positively charged ZIF-8 surface and the negatively charged site of RDB increase as $\mathrm{pH}$ of solution increases up to $\mathrm{pH}_{\mathrm{ZPC}}$. The adsorption capacity of ZIF-8 and Fe-ZIF-8 started to decrease significantly at $\mathrm{pH}>\sim 10.2$, which was probably due to the electrostatic repulsion of negatively charged $\mathrm{RDB}$ and negative ZIF-8. In addition, the low stability of ZIF-8 framework in $\mathrm{pH}$ lower than 3 also contributes to the low RDB adsorption capacity (see Figure 6). This electrostatic interaction mechanism is similar to the adsorption mechanism for phthalic acid [67] and p-arsanilic acid on ZIF-8 [27]. In addition, the hydrophobic and $\pi-\pi$ interaction between the aromatic rings of the $\mathrm{RDB}$ and the aromatic imidazole rings of the ZIF-8 framework is also thought to contribute to the RDB adsorption capacity.
The increasing RDB uptake of Fe-ZIF-8 is probably due to the adsorption through other mechanisms addition to the electrostatic interaction. The enhanced adsorbed amount with Fe-ZIF-8 probably resulted from an increased number of adsorption iron sites. It is likely that the coordination of the nitrogen atoms and oxygen in $\mathrm{RDB}$ molecules to the $\mathrm{Fe}^{2+}$ ions in the ZIF-8 framework is responsible for the more efficient adsorption compared with bare ZIF-8. From this discussion the possible mechanisms of RDB adsorption onto ZIF-8 or Fe-ZIF-8 were illustrated in Figure 11.

3.2.3. Isotherm Adsorption Studies. The study of adsorption isotherms is helpful in determining the adsorption capacities for removal at certain dyes at fixed temperature. In the present work, the equilibrium experiments were operated as if the initial concentration $\left(C_{0}=50 \mathrm{mg} \cdot \mathrm{L}^{-1}\right)$ was kept constant and the absorbent weight varied between $0.005,0.007,0.01$, $0.12,0.015,0.017$, and $0.020 \mathrm{~g}$. The experimental data were analyzed according to the nonlinear form of Langmuir and Freundlich model. Figure 12 presents the experimental points and nonlinear regression curves of Langmuir and Freundlich models. The parameters of models are listed in Table 9. However, the maximum adsorption capacity is not obtained in Freundlich equation. Halsey [68] supposed that the maximum adsorption capacity, $q_{m}$, by Freundlich equation could be expressed:

$$
q_{m}=\lim _{C_{e} \rightarrow C_{0}} K_{F} C_{e}^{1 / n}
$$

$q_{m}$ calculated based on Freundlich equation is also shown in Table 9. 

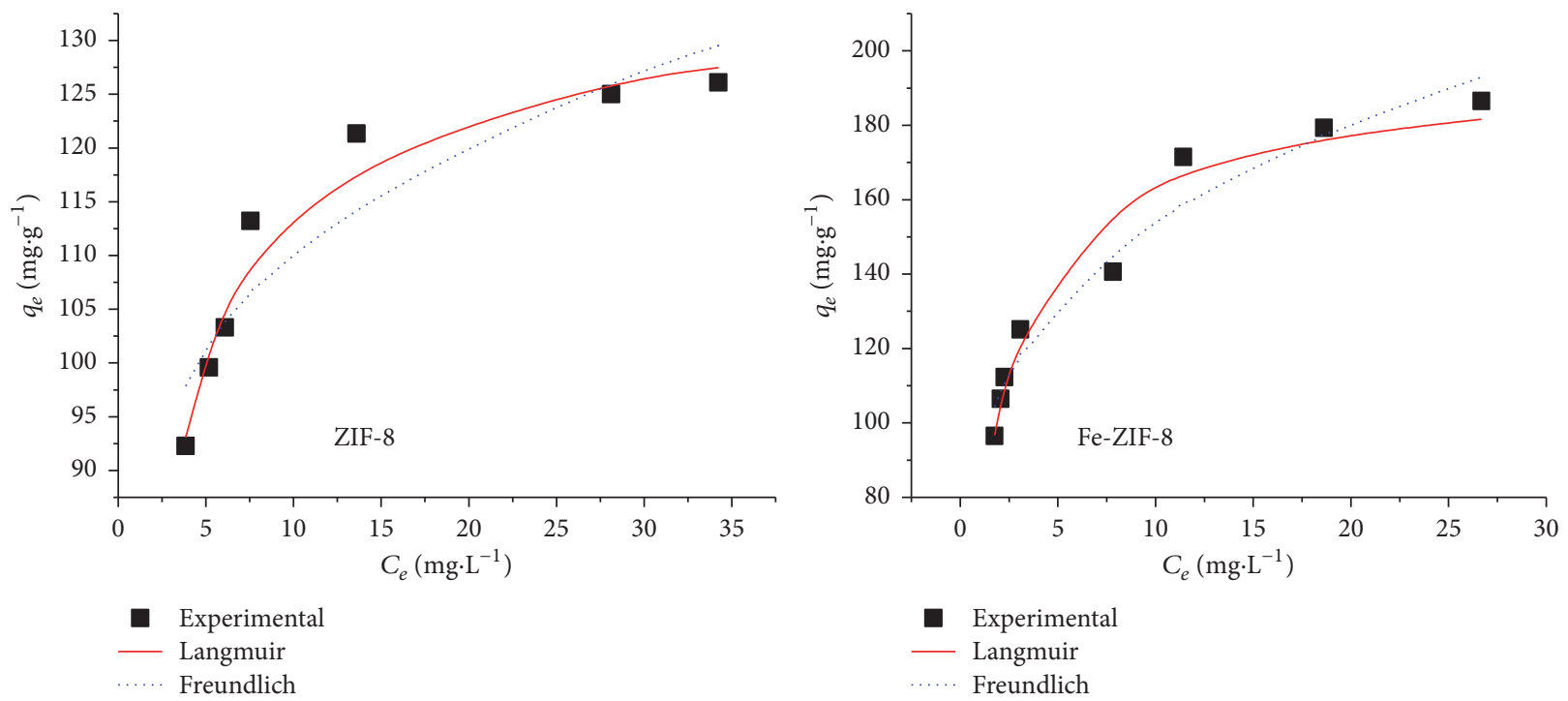

Figure 12: Langmuir and Freundlich isotherm models of adsorption RDB dye onto ZIF-8 and Fe-ZIF-8 $\left(C_{\mathrm{RDB}}=50 \mathrm{mg} \cdot \mathrm{L}^{-1} ; \mathrm{V}=40 \mathrm{~mL}\right.$; $m_{\text {adsorbent }}=0.005-0.020 \mathrm{~g} ; \mathrm{pH}=8.2$; shaking time $=24$ hours $)$.

TABLE 9: The parameters of Langmuir and Freundlich models.

\begin{tabular}{lccccccrrr}
\hline & \multicolumn{3}{c}{ Langmuir model } & & & \multicolumn{3}{c}{ Freundlich model } \\
Adsorbent & $\begin{array}{c}K_{L} \\
\left(\mathrm{~L} \cdot \mathrm{mg}^{-1}\right)\end{array}$ & $\begin{array}{c}q_{\mathrm{mom}} \\
\left(\mathrm{mg} \cdot \mathrm{g}^{-1}\right)\end{array}$ & $R^{2}$ & $\chi^{2}$ & $N$ & $\begin{array}{c}K_{F} \\
(\mathrm{mg} \cdot\end{array}$ & $\begin{array}{c}q_{m} \\
\left(\mathrm{mg} \cdot \mathrm{g}^{-1}\right)\end{array}$ & $R^{2}$ \\
\hline ZIF-8 & 0.594 & 133.76 & 0.974 & 0.254 & 7.800 & 82.344 & 127.35 & 0.878 & 1.209 \\
Fe-ZIF-8 & 0.568 & 193.56 & 0.958 & 2.340 & 4.434 & 92.015 & 222.33 & 0.961 \\
\hline
\end{tabular}

The determination coefficient $\left(R^{2}\right)$ and the Chi-square test $\left(\chi^{2}\right)$ for assessing the compatibility of experimental data with the isothermal models are listed in Table 9. The high value of $R^{2}$ and low $\chi^{2}$ suggest that the isothermal data of ZIF-8 could be well represented by the Langmuir model. This implies a monolayer adsorption for ZIF-8. For Fe-ZIF-8 both models exhibited similar values of $R^{2}$ and $\chi^{2}$. Moreover, favorable characteristic parameters of $R_{L}$ for Langmuir isotherm and $n$ for Freundlich isotherm were $0<$ $R_{L}=0.034<1$ and $2<n=4.43<10$, which indicated that both isotherms were favorable. These results confirmed that the equilibrium data of RDB adsorption onto Fe-ZIF- 8 could be well fitted by the two adsorption isotherm models. This result indicated a monolayer adsorption and the existence of heterogeneous surface in Fe-ZIF-8. It is worth noting that maximum monolayer adsorption capacity, $q_{\text {mom }}$, for ZIF- 8 is much higher than that for ZIF-8. It was concluded that the introduction of iron into ZIF-8 enhanced the RDB adsorption onto Fe-ZIF-8 in terms of kinetics and isotherm adsorption.

$K_{L}$ in Langmuir model is the equilibrium constant and describes the relation between kinetics and thermodynamics. Then, $K_{L}$ in Langmuir model is thought to be equivalent to $K_{o}$. However, the relation of $K_{L}$ and $K_{o}\left(K_{0}=k_{1} / k_{2}\right)$ (see Table 5) was not clear in our study. It is explained by that fact that in the solid-liquid adsorption system $K_{L}$ in the Langmuir model no longer reflects the equilibrium constant as its original meaning. In our previous study [40], as isothermal adsorption experiments were operated with constant initial concentration $C_{0}$ and variable weights of adsorbent, we found that the obtained parameters of Langmuir and Freundlich models also increase as the initial concentration increases, which should be constant at certain temperature. It is thought that these parameters turn out to be empirical coefficients rather than fixed parameters at a certain temperature.

3.2.4. Reusability of ZIF-8 and Fe-ZIF-8. To estimate the reusability of ZIF- 8 and Fe-ZIF- 8 for the removal RDB, the used adsorbents were regenerated by sonication assisted washing with $10^{-3} \mathrm{M} \mathrm{NaOH}$ solution for $6 \mathrm{~h}$ and drying for 24 hours at $100^{\circ} \mathrm{C}$ and then exploited to adsorb RDB. The adsorption capacity of the regenerated ZIF-8 and Fe-ZIF-8 are presented in Figure 13. Although the RDB adsorption decreased gradually with an increase in desorption cycles, the regenerated adsorbents still exhibited good performance for their adsorption. After the desorption for three cycles, the RDB adsorption capacity of by ZIF-8 and Fe-ZIF-8 reached $90 \%$ and $95 \%$ of the adsorption of the initial material, respectively. The XRD patterns of adsorbents after the three cycles seem unchangeable (see Figure 14), indicating that the adsorbents were stable in this condition. 

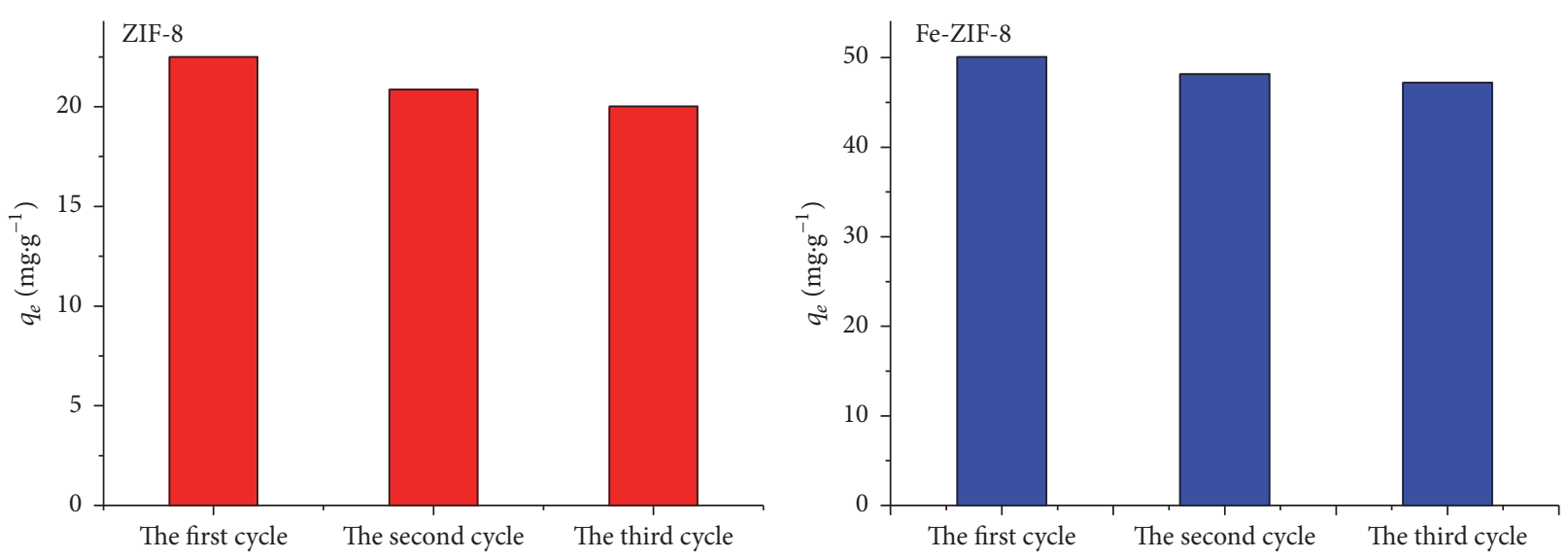

FIGURE 13: Effect of regeneration cycles of ZIF-8 and Fe-ZIF-8 adsorbents on the adsorption of RDB $\left(V_{\mathrm{RDB}}=125 \mathrm{~mL} ; C_{\mathrm{RDB}}=50 \mathrm{mg} \mathrm{L}{ }^{-1}\right.$; adsorbent $/ V_{\mathrm{RDB}}=0.05 \mathrm{~g} / 125 \mathrm{~mL}$; shaking time $=10$ hours $)$.
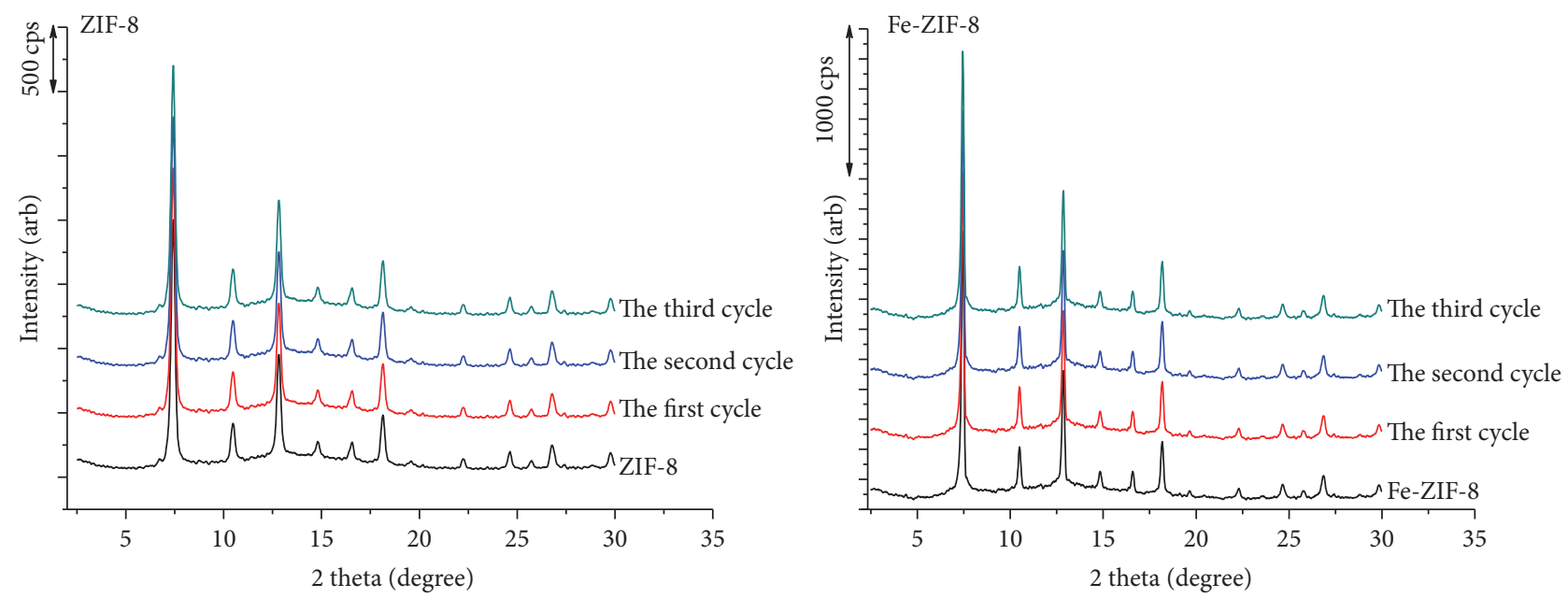

FIgURE 14: The XRD patterns of ZIF-8 and Fe-ZIF-8 adsorbents after the three cycles.

\section{Conclusion}

The iron doped zeolite imidazolate framework- 8 was synthesized by hydrothermal process. Ferrous ion as an iron source could be directly introduced into ZIF-8 to form FeZIF-8 (molar mole of $\mathrm{Fe} /(\mathrm{Fe}+\mathrm{Zn})=0.116)$. The ferrous ions could replace partially $\mathrm{Zn}$ (II) in ZIF-8 structure or exist in amorphous species. The ZIF-8 was stable in aqueous solutions with $\mathrm{pH}$ in ranging from 3 to 12 for 24 hours. Both ZIF- 8 and Fe-ZIF- 8 were used to study the RDB adsorption. The results show that the introduction of iron into ZIF-8 significantly enhanced the RDB adsorption capacity compared to bare ZIF-8. The study based on Webber's intraparticle diffusion shows that the adsorption process with ZIF-8 and Fe-ZIF8 tended to follow two stages in which the first stage was film-diffusion and the second was an intraparticle-diffusion process. The kinetic parameters based on Arrhenius and Eyring equation proved that the introduction of iron into ZIF-8 provided a much larger adsorption capacity and faster adsorption kinetics than ZIF-8. In addition to the electrostatic interaction mechanism and the hydrophobic and $\pi-\pi$ interaction between the aromatic rings of the $\mathrm{RBB}$ dye and the aromatic imidazole rings of the adsorbent for ZIF8 , the coordination of the nitrogen atoms and oxygen in carboxyl group in $\mathrm{RDB}$ molecules to the $\mathrm{Fe}^{2+}$ ions in the ZIF-8 framework might explain why Fe-ZIF-8 has a higher RBD adsorption capacity than ZIF-8. The experimental data for ZIF-8 were well correlated by Langmuir model while those for Fe-ZIF-8 were well fitted to both Langmuir and Freundlich models. The maximum monolayer adsorption capacity for Fe-ZIF-8 $\left(193.56 \mathrm{mg}^{-1} \cdot \mathrm{g}^{-1}\right)$ was approximately 1.4 times higher than that for ZIF-8 $\left(133.76 \mathrm{mg}^{-1} \cdot \mathrm{g}^{-1}\right)$.

\section{Conflicts of Interest}

The authors declare that they have no conflicts of interest.

\section{Acknowledgments}

This work was funded by Ministry of Education and Training, Vietnam, under the Project B2016-DHH-20. 


\section{References}

[1] F. P. Van Der Zee and S. Villaverde, "Combined anaerobicaerobic treatment of azo dyes-a short review of bioreactor studies," Water Research, vol. 39, no. 8, pp. 1425-1440, 2005.

[2] P. A. Soloman, C. A. Basha, M. Velan, V. Ramamurthi, K. Koteeswaran, and N. Balasubramanian, "Electrochemical degradation of Remazol Black B Dye effluent," Clean-Soil, Air, Water, vol. 37, no. 11, pp. 889-900, 2009.

[3] N. F. Cardoso, R. B. Pinto, E. C. Lima et al., "Removal of remazol black B textile dye from aqueous solution by adsorption," Desalination, vol. 269, no. 1-3, pp. 92-103, 2011.

[4] V. R. Ranjusha, R. Pundir, K. Kumar, M. G. Dastidar, and T. R. Sreekrishnan, "Biosorption of Remazol Black B dye (Azo dye) by the growing Aspergillus flavus," Journal of Environ Sci Health A: Toxic/Hazardous Substances and Environmental Engineering, vol. 45, no. 10, pp. 1256-1263, 2010.

[5] C. Janiak and J. K. Vieth, "MOFs, MILs and more: concepts, properties and applications for porous coordination networks (PCNs)," New Journal of Chemistry, vol. 34, no. 11, pp. 23662388, 2010.

[6] O. M. Yaghi, M. O'Keeffe, N. W. Ockwig, H. K. Chae, M. Eddaoudi, and J. Kim, "Reticular synthesis and the design of new materials," Nature, vol. 423, no. 6941, pp. 705-714, 2003.

[7] P. Chowdhury, C. Bikkina, and S. Gumma, "Gas adsorption properties of the chromium-based metal organic framework MIL-101," Journal of Physical Chemistry C, vol. 113, no. 16, pp. 6616-6621, 2009.

[8] L. Hamon, C. Serre, T. Devic et al., "Comparative study of hydrogen sulfide adsorption in the MIL-53(Al, Cr, Fe), MIL47(V), MIL-100(Cr), and MIL-101(Cr) metal-organic frameworks at room temperature," Journal of the American Chemical Society, vol. 131, no. 25, pp. 8775-8777, 2009.

[9] Y. Li and R. T. Yang, "Hydrogen storage in metal-organic and covalent-organic frameworks by spillover," AIChE Journal, vol. 54, no. 1, pp. 269-279, 2008.

[10] P. L. Llewellyn, S. Bourrelly, C. Serre et al., "High uptakes of CO2 and $\mathrm{CH} 4$ in mesoporous metal-organic frameworks MIL-100 and MIL-101," Langmuir, vol. 24, no. 14, pp. 7245-7250, 2008.

[11] J. Yang, Q. Zhao, J. Li, and J. Dong, "Synthesis of metal-organic framework MIL-101 in TMAOH-Cr( $\left(\mathrm{NO}_{3}\right)_{3}-\mathrm{H}_{2} \mathrm{BDC}-\mathrm{H}_{2} \mathrm{O}$ and its hydrogen-storage behavior," Microporous and Mesoporous Materials, vol. 130, no. 1-3, pp. 174-179, 2010.

[12] K. Yang, Q. Sun, F. Xue, and D. Lin, "Adsorption of volatile organic compounds by metal-organic frameworks MIL-101: influence of molecular size and shape," Journal of Hazardous Materials, vol. 195, pp. 124-131, 2011.

[13] Z. Zhang, S. Huang, S. Xian, H. Xi, and Z. Li, "Adsorption equilibrium and kinetics of $\mathrm{CO}_{2}$ on chromium terephthalate MIL-101," Energy and Fuels, vol. 25, no. 2, pp. 835-842, 2011.

[14] R. Kitaura, K. Seki, G. Akiyam, and S. Kitagawa, "Porous coordination-polymer crystals with gated channels specific for supercritical gases," Angewandte Chemie-International Edition, vol. 42, no. 4, pp. 428-431, 2003.

[15] S. Ma, D. Sun, X.-S. Wang, and H.-C. Zhou, "A mesh-adjustable molecular sieve for general use in gas separation," Angewandte Chemie-International Edition, vol. 46, no. 14, pp. 2458-2462, 2007.

[16] D.-Y. Hong, Y. K. Hwang, C. Serre, G. Férey, and J.-S. Chang, "Porous chromium terephthalate MIL-101 with coordinatively unsaturated sites: surface functionalization, encapsulation, sorption and catalysis," Advanced Functional Materials, vol. 19, no. 10, pp. 1537-1552, 2009.

[17] Y. K. Hwang, D.-Y. Hong, J.-S. Chang et al., "Selective sulfoxidation of aryl sulfides by coordinatively unsaturated metal centers in chromium carboxylate MIL-101," Applied Catalysis A: General, vol. 358, no. 2, pp. 249-253, 2009.

[18] N. V. Maksimchuk, M. N. Timofeev, M. S. Melgunov et al., "Heterogeneous selective oxidation catalysts based on coordination polymer MIL-101 and transition metal-substituted polyoxometalates," Journal of Catalysis, vol. 257, no. 2, pp. 315323, 2008.

[19] Z. Saedi, S. Tangestaninejad, M. Moghadam, V. Mirkhani, and I. Mohammadpoor-Baltork, "MIL-101 metal-organic framework: a highly efficient heterogeneous catalyst for oxidative cleavage of alkenes with $\mathrm{H}_{2} \mathrm{O}_{2}$," Catalysis Communications, vol. 17, pp. 18-22, 2012.

[20] A. Phan, C. J. Doonan, F. J. Uribe-Romo, C. B. Knobler, M. O'Keeffe, and O. M. Yaghi, "Synthesis, structure, and carbon dioxide capture properties of zeolitic imidazolate frameworks," Accounts of Chemical Research, vol. 43, no. 1, pp. 58-67, 2010.

[21] J. R. Long and O. M. Yaghi, "The pervasive chemistry of metalorganic frameworks," Chemical Society Reviews, vol. 38, no. 5, pp. 1213-1214, 2009.

[22] H. Wu, W. Zhou, and T. Yildirim, "Hydrogen storage in a prototypical zeolitic imidazolate framework-8," Journal of the American Chemical Society, vol. 129, no. 17, pp. 5314-5315, 2007.

[23] H. Bux, A. Feldhoff, J. Cravillon, M. Wiebcke, Y.-S. Li, and J. Caro, "Oriented zeolitic imidazolate framework- 8 membrane with sharp $\mathrm{H}_{2} / \mathrm{C}_{3} \mathrm{H}_{8}$ molecular sieve separation," Chemistry of Materials, vol. 23, no. 8, pp. 2262-2269, 2011.

[24] J. Cravillon, S. Münzer, S.-J. Lohmeier, A. Feldhoff, K. Huber, and M. Wiebcke, "Rapid room-temperature synthesis and characterization of nanocrystals of a prototypical zeolitic imidazolate framework," Chemistry of Materials, vol. 21, no. 8, pp. 1410-1412, 2009.

[25] J.-Q. Jiang, C.-X. Yang, and X.-P. Yan, “Zeolitic imidazolate framework-8 for fast adsorption and removal of benzotriazoles from aqueous solution," ACS Applied Materials and Interfaces, vol. 5, no. 19, pp. 9837-9842, 2013.

[26] K.-Y. A. Lin and H.-A. Chang, "Efficient adsorptive removal of humic acid from water using zeolitic imidazole framework-8 (ZIF-8)," Water, Air, and Soil Pollution, vol. 226, article 10, 2015.

[27] B. K. Jung, J. W. Jun, Z. Hasan, and S. H. Jhung, "Adsorptive removal of p-arsanilic acid from water using mesoporous zeolitic imidazolate framework-8," Chemical Engineering Journal, vol. 267, pp. 9-15, 2015.

[28] M. Jian, B. Liu, G. Zhang, R. Liu, and X. Zhang, "Adsorptive removal of arsenic from aqueous solution by zeolitic imidazolate framework-8 (ZIF-8) nanoparticles," Colloids and Surfaces A: Physicochemical and Engineering Aspects, vol. 465, pp. 67-76, 2015.

[29] J. Zheng, C. Cheng, W.-J. Fang et al., "Surfactant-free synthesis of a $\mathrm{Fe}_{3} \mathrm{O}_{4} @ \mathrm{ZIF}-8$ core-shell heterostructure for adsorption of methylene blue," CrystEngComm, vol. 16, no. 19, pp. 3960-3964, 2014.

[30] S. Eslava, L. Zhang, S. Esconjauregui et al., "Metal-organic framework ZIF-8 films as low- $\kappa$ dielectrics in microelectronics," Chemistry of Materials, vol. 25, no. 1, pp. 27-33, 2013.

[31] M. Zhu, S. R. Venna, J. B. Jasinski, and M. A. Carreon, "Room-temperature synthesis of ZIF-8: the coexistence of $\mathrm{ZnO}$ nanoneedles," Chemistry of Materials, vol. 23, no. 16, pp. 35903592, 2011. 
[32] A. Kumar, B. Prasad, and I. M. Mishra, "Adsorptive removal of acrylonitrile by commercial grade activated carbon: kinetics, equilibrium and thermodynamics," Journal of Hazardous Materials, vol. 152, no. 2, pp. 589-600, 2008.

[33] N. Kannan and M. Meenakshisundaram, "Adsorption of Congo Red on various activated carbons. A Comparative Study," Water, Air, and Soil Pollution, vol. 138, no. 1-4, pp. 289-305, 2002.

[34] A. J. Ahamed, V. Balakrishman, and S. Arivoli, "Kinetic and equilibrium studies of Rhodamine B adsorption by low cost activated carbon," Archives of Applied Science Research, vol. 3, pp. 154-166, 2011.

[35] P. Atkins and J. D. Paula, Physical Chemistry, Oxford University Press, New York, NY, USA, 2010.

[36] J. Crank, The Mathematics of Diffusion, Clarendon Press, London, UK, 1975.

[37] W. J. Weber and J. C. Morris, "Kinetics of adsorption on carbon from solution," Journal of the Sanitary Engineering Division Proceed American society of civil Engineers, vol. 89, no. 2, pp. 3160, 1963.

[38] G. F. Malash and M. I. El-Khaiary, "Piecewise linear regression: a statistical method for the analysis of experimental adsorption data by the intraparticle-diffusion models," Chemical Engineering Journal, vol. 163, no. 3, pp. 256-263, 2010.

[39] H. Motulsky and A. Christopoulos, Fitting Models to Biological Data Using Linear and Non-Linear Regression, GraphPad Software, San Diego, Calif, USA, 2003.

[40] B. H. Dang Son, V. Quang Mai, D. Xuan Du, N. Hai Phong, and D. Quang Khieu, "A study on astrazon black AFDL dye adsorption onto Vietnamese diatomite," Journal of Chemistry, vol. 2016, Article ID 8685437, 11 pages, 2016.

[41] T. S. Anirudhan and P. G. Radhakrishnan, “Thermodynamics and kinetics of adsorption of $\mathrm{Cu}(\mathrm{II})$ from aqueous solutions onto a new cation exchanger derived from tamarind fruit shell," The Journal of Chemical Thermodynamics, vol. 40, no. 4, pp. 702-709, 2008.

[42] K. G. Scheckel and D. L. Sparks, “Temperature effects on nickel sorption kinetics at the mineral-water interface," Soil Science Society of America Journal, vol. 65, no. 3, pp. 719-728, 2001.

[43] E. I. Unuabonah, K. O. Adebowale, and B. I. Olu-Owolabi, "Kinetic and thermodynamic studies of the adsorption of lead (II) ions onto phosphate-modified kaolinite clay," Journal of Hazardous Materials, vol. 144, no. 1-2, pp. 386-395, 2007.

[44] Y. Liu, "Is the free energy change of adsorption correctly calculated?" Journal of Chemical and Engineering Data, vol. 54, no. 7, pp. 1981-1985, 2009.

[45] Q. Song, S. K. Nataraj, M. V. Roussenova et al., "Zeolitic imidazolate framework (ZIF-8) based polymer nanocomposite membranes for gas separation," Energy and Environmental Science, vol. 5, no. 8, pp. 8359-8369, 2012.

[46] I. Langmuir, "The constitution and fundamental properties of solids and liquids. Part I. Solids," The Journal of the American Chemical Society, vol. 38, no. 2, pp. 2221-2295, 1916.

[47] T. W. Weber and R. K. Chakravorti, "Pore and solid diffusion models for fixed-bed adsorbers," AIChE Journal, vol. 20, no. 2, pp. 228-238, 1974.

[48] H. M. F. Freundlich, "Over the adsorption in solution," Journal of Physical Chemistry, vol. 57, pp. 385-471, 1906.

[49] I. Tosun, "Ammonium removal from aqueous solutions by clinoptilolite: determination of isotherm and thermodynamic parameters and comparison of kinetics by the double exponential model and conventional kinetic models," International
Journal of Environmental Research and Public Health, vol. 9, no. 3, pp. 970-984, 2012.

[50] I. A. W. Tan, A. L. Ahmad, and B. H. Hameed, "Adsorption of basic dye on high-surface-area activated carbon prepared from coconut husk: equilibrium, kinetic and thermodynamic studies," Journal of Hazardous Materials, vol. 154, no. 1-3, pp. 337-346, 2008.

[51] A. Asfaram, M. Ghaedi, and G. R. Ghezelbash, "Biosorption of $\mathrm{Zn}^{2+}, \mathrm{Ni}^{2+}$ and $\mathrm{Co}^{2+}$ from water samples onto Yarrowia lipolytica ISF7 using a response surface methodology, and analyzed by inductively coupled plasma optical emission spectrometry (ICP-OES)," RSC Advances, vol. 6, no. 28, pp. 23599-23610, 2016.

[52] O. Karagiaridi, M. B. Lalonde, W. Bury, A. A. Sarjeant, O. K. Farha, and J. T. Hupp, "Opening ZIF-8: a catalytically active zeolitic imidazolate framework of sodalite topology with unsubstituted linkers," Journal of the American Chemical Society, vol. 134, no. 45, pp. 18790-18796, 2012.

[53] Y. Du, R. Z. Chen, J. F. Yao, and H. T. Wang, "Facile fabrication of porous $\mathrm{ZnO}$ by thermal treatment of zeolitic imidazolate framework-8 and its photocatalytic activity," Journal of Alloys and Compounds, vol. 551, no. 25, pp. 125-130, 2013.

[54] X. Zeng, L. Huang, C. Wang, J. Wang, J. Li, and X. Luo, "Sonocrystallization of ZIF-8 on electrostatic spinning $\mathrm{TiO}_{2}$ nanofibers surface with enhanced photocatalysis property through synergistic effect," ACS Applied Materials and Interfaces, vol. 8, no. 31, pp. 20274-20282, 2016.

[55] V. Vadivelan and K. Vasanth Kumar, "Equilibrium, kinetics, mechanism, and process design for the sorption of methylene blue onto rice husk," Journal of Colloid and Interface Science, vol. 286, no. 1, pp. 90-100, 2005.

[56] G. A. Seber and C. J. Wild, Nonlinear Regression, Wiley Series in Probability and Mathematical Statistics: Probability and Mathematical Statistics, John Wiley \& Sons, New York, NY, USA, 1989.

[57] M. A. Al-Ghouti, M. A. M. Khraisheh, M. N. M. Ahmad, and S. Allen, "Adsorption behaviour of methylene blue onto Jordanian diatomite: a kinetic study," Journal of Hazardous Materials, vol. 165, no. 1-3, pp. 589-598, 2009.

[58] A. J. Ahamed and B. J. Suganthana, "Adsorption of Cr-VI on commercially available ash powder-a kinetic approach," Journal of the Indian Chemical Society, vol. 83, pp. 792-795, 2006.

[59] B. Y. M. Bueno, M. L. Torem, F. Molina, and L. M. S. de Mesquita, "Biosorption of lead(II), chromium(III) and copper(II) by R. opacus: equilibrium and kinetic studies," Minerals Engineering, vol. 21, no. 1, pp. 65-75, 2008.

[60] C. E. Webster, R. S. Drago, and M. C. Zerner, "Molecular dimensions for adsorptives," Journal of the American Chemical Society, vol. 120, no. 22, pp. 5509-5516, 1998.

[61] R. R. Sheha and A. A. El-Zahhar, "Synthesis of some ferromagnetic composite resins and their metal removal characteristics in aqueous solutions," Journal of Hazardous Materials, vol. 150, no. 3, pp. 795-803, 2008.

[62] N. K. Lazaridis, T. D. Karapantsios, and D. Georgantas, "Kinetic analysis for the removal of a reactive dye from aqueous solution onto hydrotalcite by adsorption," Water Research, vol. 37, no. 12, pp. 3023-3033, 2003.

[63] Y. S. Ho and G. McKay, "Pseudo-second order model for sorption processes," Process Biochemistry, vol. 34, no. 5, pp. 451465, 1999. 
[64] J. X. Lin, S. L. Zhan, M. H. Fang, and X. Q. Qian, "The adsorption of dyes from aqueous solution using diatomite," Journal of Porous Materials, vol. 14, no. 4, pp. 449-455, 2007.

[65] K. G. Scheckel and D. L. Sparks, "Dissolution kinetics of nickel surface precipitates on clay mineral and oxide surfaces," Soil Science Society of America Journal, vol. 66, pp. 689-694, 2001.

[66] C.-C. Kan, M. C. Aganon, C. M. Futalan, and M. L. P. Dalida, "Adsorption of $\mathrm{Mn}^{2+}$ from aqueous solution using fe and $\mathrm{mn}$ oxide-coated sand," Journal of Environmental Sciences, vol. 25, no. 7, pp. 1483-1491, 2013.

[67] N. A. Khan, B. K. Jung, Z. Hasan, and S. H. Jhung, "Adsorption and removal of phthalic acid and diethyl phthalate from water with zeolitic imidazolate and metal-organic frameworks," Journal of Hazardous Materials, vol. 282, pp. 194-200, 2015.

[68] G. D. Halsey, "The role of surface heterogeneity in adsorption," Advances in Catalysis, vol. 4, pp. 259-269, 1952. 

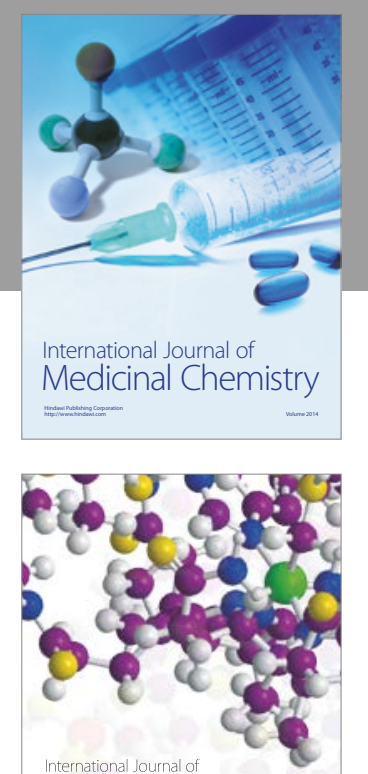

Carbohydrate Chemistry

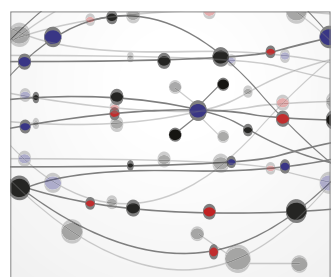

The Scientific World Journal
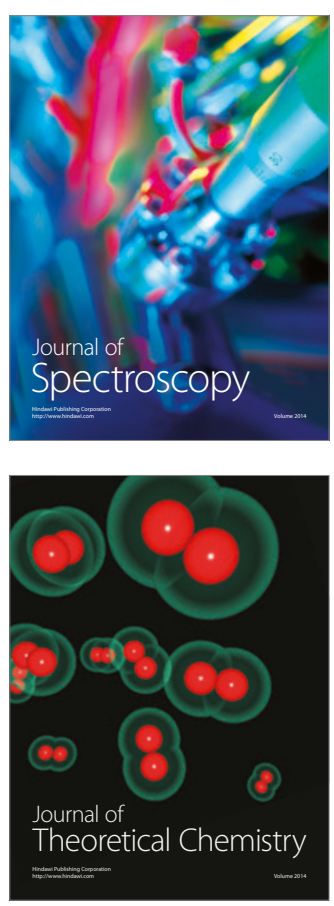
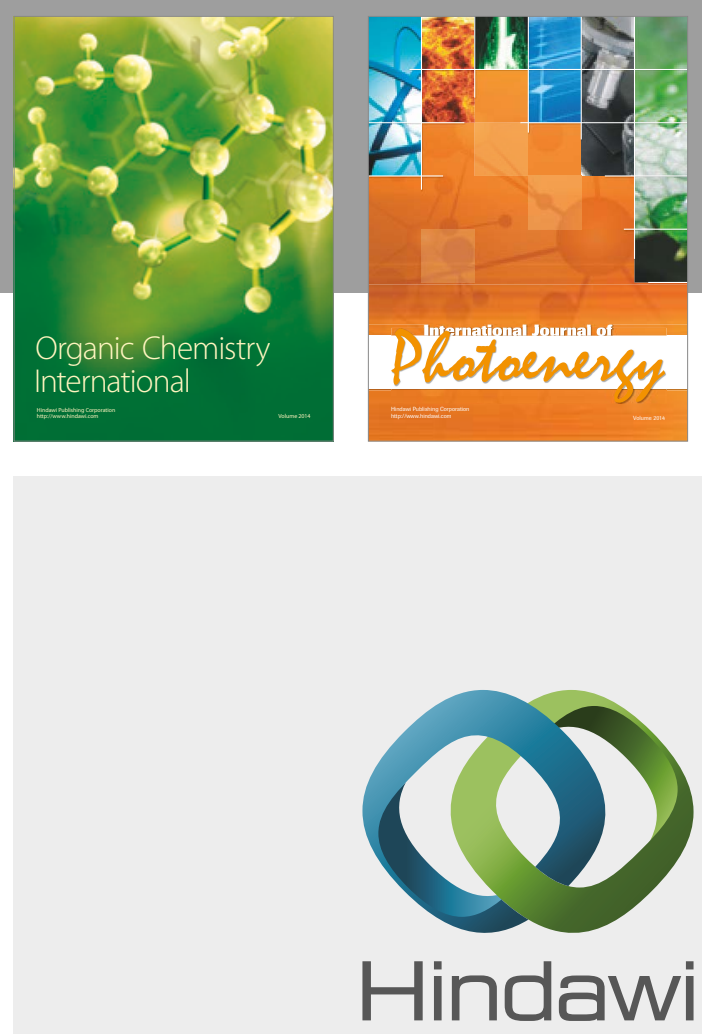

Submit your manuscripts at

https://www.hindawi.com

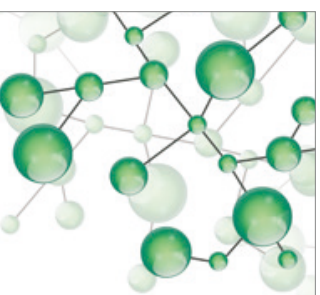

International Journal of

Inorganic Chemistry

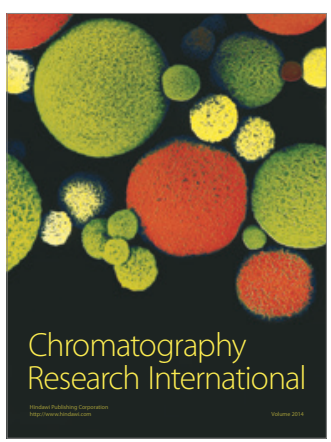

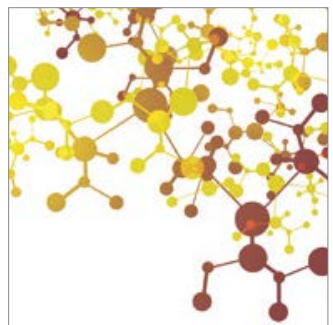

Applied Chemistry
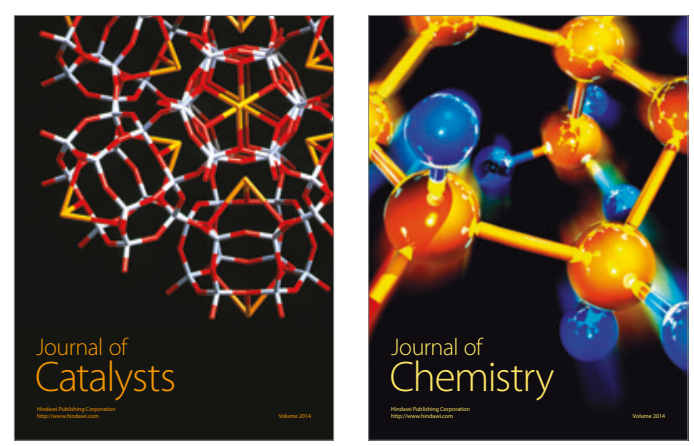
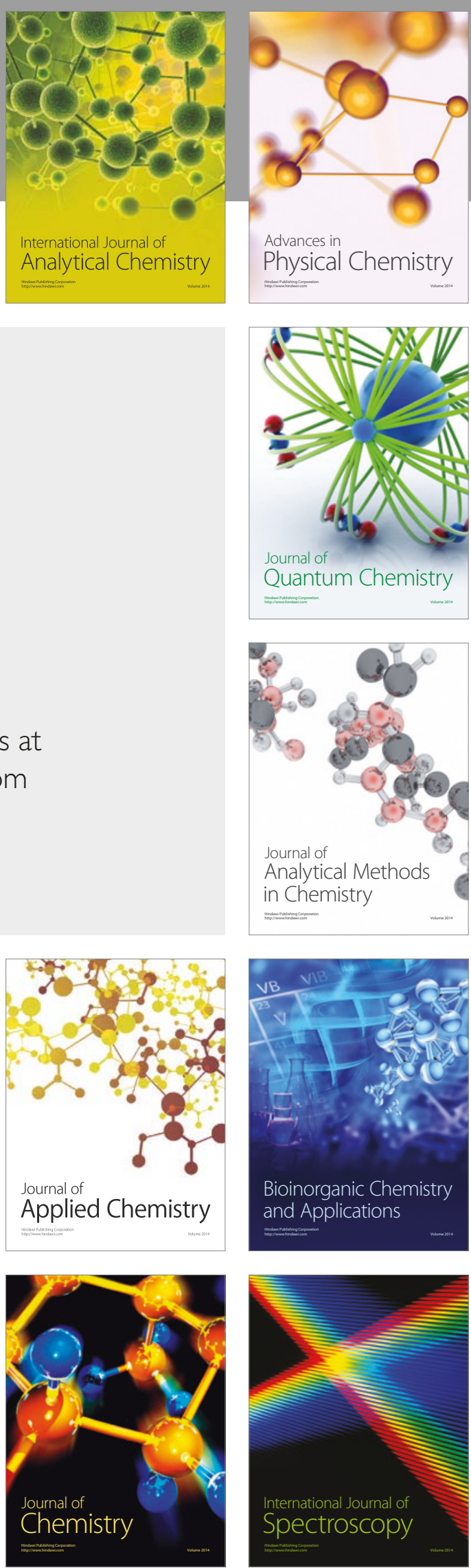